\title{
COMÉRCIO E MEIO AMBIENTE: POLÍTICAS AMBIENTAIS E COMPETITIVIDADE NO ÂMBITO DA ALCA
}

Flavio Tosi Feijó ${ }^{\S}$

André Filipe Zago de Azevedo

\section{RESUMO}

Este artigo avalia de forma integrada os efeitos da ALCA e das reduções de emissões de $\mathrm{CO}_{2}$, tratadas pelo Protocolo de Quioto, a fim de se fazer uma comparação dos benefícios (ou perdas), tanto econômicos quanto ambientais. O instrumento utilizado para as simulações - GTAP-E (energia) - é uma versão modificada do GTAP (Global Trade Analysis Project) desenvolvido pela Universidade de Purdue e foi projetado para analisar assuntos relacionados ao uso de energia e de políticas que provoquem mudanças climáticas. Os resultados obtidos apontam que a política ambiental de redução de emissões, apesar de contribuir para a diminuição de $\mathrm{CO}_{2}$ na atmosfera, de forma geral, afeta negativamente o bem-estar econômico nos países que contraem tais emissões. Este resultado sugere que um determinado país que adotasse um comportamento free rider na hipótese de consolidação da ALCA, não reduzindo suas emissões, seria beneficiado em relação aos demais países que adotassem outra postura.

Palavras-chave: comércio e meio ambiente, Protocolo de Quioto, Área de Livre-Comércio das Américas, GTAP-E, emissões de $\mathrm{CO}_{2}$.

\begin{abstract}
This paper analyses the effects of both the FTAA and the reduction of $\mathrm{CO}_{2}$ emissions, established by the Kyoto Protocol, in order to compare the gains (or losses) on economic and environmental grounds. The instrument employed to perform the simulations are based on GTAP-E (energy), a modified version of GTAP (Global Trade Analysis Project) developed by the Purdue University, which aims to assess the issues related to the use of energy and the impacts of policies that generate climate changes. The results show that environment policies that reduce $\mathrm{CO}_{2}$ emissions despite contributing to $\mathrm{cut}^{\mathrm{CO}_{2}}$ on the atmosphere, in general affect negatively the economic welfare on countries that contract such emissions. This result suggests that if a country adopts a free rider behavior towards the FTAA, not reducing its emissions, it would be benefited in relation to other countries that do not adopt this position.
\end{abstract}

Key words: trade and environment, Kyoto Protocol, Free Trade Area of the Americas GTAP-E, $\mathrm{CO}_{2}$ emissions.

JEL classification: F18, Q56.

$\S$ Professor Adjunto da Fundação Universidade Federal do Rio Grande (FURG). Doutor em Economia pela Universidade Federal do Rio Grande do Sul (UFRGS). Endereço para contato: Rua Matias José Bins, 916/301 - Três Figueiras - Porto Alegre - RS - Cep: 91330-290.E-mail: tosifl@yahoo.com.br.

a Coordenador do Mestrado em Economia da Universidade do Vale do Rio dos Sinos (UNISINOS). Doutor em Economia pela University of Sussex (Reino Unido). Endereço para contato: Av. Unisinos, 950, sala 5A - 410 - São Leopoldo - RS - Cep: 93022000.E-mail: aazevedo@unisinos.br.

Recebido em maio de 2006. Aprovado em agosto de 2006. 


\section{INTRODUÇÃO}

O tema comércio e meio ambiente é um campo extremamente fértil e tem sido objeto de estudo de vários pesquisadores ao redor do mundo. Os ramos nos quais esse tema se divide abrangem as mais variadas situações: os efeitos do comércio sobre o meio ambiente (poluição do ar, água e uso da terra); a política ambiental sobre a competitividade dos países via internalização dos custos ambientais; as medidas ambientais com propósitos de proteção comercial; e as medidas comerciais com propósitos ambientais. Estas abordagens podem ser encontradas, por exemplo, em Grossman e Krueger (1993), Tobey (1990) e Antweiler, Copeland e Taylor (1998). Assim se, por um lado, temse a abertura comercial como possível indutora da degradação ambiental, por outro, pode-se ter os padrões de exigências ambientais afetando a competitividade dos países.

A forma como o comércio internacional afeta o meio ambiente das nações e o impacto das políticas ambientais adotadas unilateralmente sobre a competitividade dos mesmos ainda são questões que carecem de maior investigação empírica. Os resultados encontrados na literatura pertinente são ainda muito controversos. A despeito desta discussão, um fenômeno que tem suscitado o debate no mundo devido ao seu caráter de urgência é o aquecimento global causado pelas emissões dos gases causadores do efeito estufa. Nesta discussão, o comércio internacional tem também um lugar de destaque.

Um dos instrumentos econômicos que têm sido recentemente utilizados para avaliar essa questão é o modelo de Equilíbrio Geral Computável (EGC). Uma grande contribuição dos modelos EGC é que os mesmos podem fornecer informações ex ante para os formuladores de políticas, por meio da apresentação de cenários alternativos de situações reais. Os modelos de equilíbrio geral adotam uma solução que define uma situação econômica estável, na qual a demanda e a oferta são equalizadas em todos os setores. Esses modelos focalizam a interdependência dos mercados, possibilitando que se façam inferências sobre os impactos diretos e indiretos de externalidades de políticas de comércio e ambientais sobre os custos de produção e bem-estar do consumidor. Embora o estudo dos impactos ambientais decorrentes de acordos comerciais (e vice-versa) já seja um tema bastante pesquisado em nível mundial, no Brasil essa abordagem pode ser considerada ainda incipiente. Mais especificamente, quando se trata dessa problemática para o Brasil utilizando o instrumental de EGC, têm-se pouquíssimos trabalhos aplicados, podendo-se destacar os de Seroa da Motta (2002) e Tourinho et al. (2003). ${ }^{1}$

O objetivo deste trabalho é fazer uma avaliação integrada de um possível acordo comercial da ALCA concomitantemente às reduções de emissões de $\mathrm{CO}_{2}$ tratadas pelo Protocolo de Quioto com vistas a fazer uma comparação dos benefícios (ou perdas), tanto econômicos quanto ambientais. Portanto, serão construídos dois cenários para contemplar essas possibilidades de execução da ALCA e Protocolo de Quioto. As simulações consistirão de choques de eliminação dos gravames tarifários entre os membros do bloco, bem como de redução das emissões de $\mathrm{CO}_{2}$ para os signatários do Protocolo, admitindo ainda a possibilidade de execução de um dos mecanismos de flexibilidade do Protocolo - o comércio de emissões. A análise dos resultados procurará privilegiar os impactos sobre os membros da ALCA e, mais especificamente, o Brasil.

Além desta introdução este trabalho está organizado da seguinte maneira. Em primeiro lugar, na seção 2, far-se-á uma breve revisão do processo que culminou no Tratado de Quioto, bem como

1 O primeiro utilizou os resultados obtidos na simulação de Tourino e Kume (2002) para medir os impactos macroeconômicos e setoriais da liberação do comércio no âmbito da ALCA sobre o meio ambiente brasileiro. No segundo os autores adaptam o modelo de Tourino e Andrade (1998) por meio da inserção de um vetor de intensidade de poluição contendo coeficientes de poluição setoriais para avaliar os impactos econômicos de uma política de tributação sobre emissões de $\mathrm{CO}_{2}$ na economia brasileira. 
a participação brasileira nesse processo. A seguir, na seção 3, apresenta-se a metodologia adotada bem como a agregação utilizada para a construção dos cenários, sendo que estes últimos, assim como os principais resultados, aparecem na seção 4. Finalmente, algumas considerações finais são tecidas.

\section{COMÉRCIO INTERNACIONAL E O AQUECIMENTO GLOBAL}

A influência que o comércio internacional tem sobre o aquecimento global provém basicamente de duas fontes: primeiro, por meio das emissões de $\mathrm{CO}_{2}$, quando as mercadorias são transportadas para diferentes partes o mundo; segundo, pelo deslocamento das atividades produtivas poluidoras, que são canalizadas pelo comércio por meio de vários mecanismos de mercado. A despeito dos problemas de emissões de gases decorrentes do transporte de mercadorias que a intensificação do comércio internacional possa trazer para a atmosfera, aqui o objeto de estudo é a realocação da produção das indústrias energo-intensivas e suas emissões de carbono causadas pela abertura ao comércio internacional proporcionada pela formação da ALCA. Para introduzir esse assunto é necessário que antes se faça uma breve explanação do que vem a ser o "efeito estufa" e mudança climática.

\subsection{O aquecimento global}

O ser humano, por meio de suas atividades econômicas, principalmente após o advento da Revolução Industrial, pode estar contribuindo para o aquecimento da Terra. ${ }^{2}$ A intensificação do "efeito estufa" e as conseqüências climáticas decorrentes do aquecimento global podem trazer sérios problemas para a vida humana e o ecossistema como um todo. ${ }^{3}$ Apesar de não haver ainda um consenso sobre a magnitude da interferência humana na temperatura do Planeta (embora os cientistas advirtam que nos últimos cem anos a temperatura média da Terra aumentou aproximadamente $0,6^{\circ} \mathrm{C}$ ), esse tema tornou-se uma preocupação mundial, que culminou com o comprometimento dos países mais desenvolvidos (OCDE) em reduzir suas taxas de emissão dos gases que contribuem para o "efeito estufa".

Para que se possa entender a influência humana no clima do planeta Terra é necessário que se entenda o funcionamento do sistema climático, e como a ação humana pode interferir no mesmo. A mudança climática refere-se a uma variação estatisticamente significante, tanto no estado médio do clima quanto na sua variabilidade, e que seja persistente ao longo de décadas ou períodos mais longos. A mudança do clima pode resultar tanto de um processo interno da natureza quanto de forças externas, como as persistentes emissões "antrópicas" dos gases do "efeito estufa" na atmosfera terrestre. ${ }^{5}$ O "efeito estufa" é um processo natural que proporciona condições ideais para o desenvolvimento da vida na Terra, e é causado pela presença em concentração adequada dos seguintes gases na atmosfera: vapor d'água $\left(\mathrm{H}_{2} \mathrm{O}\right)$, ozônio $\left(\mathrm{O}_{3}\right)$, dióxido de carbono $\left(\mathrm{CO}_{2}\right)$, metano $\left(\mathrm{CH}_{4}\right)$, óxido nitroso $\left(\mathrm{N}_{2} \mathrm{O}\right)$, clorofluorcarbonos (CFCs), hidrofluorcarbonos (HFCs) e perfluorcarbonos

2 De acordo com a definição das Nações Unidas, mudança climática diz respeito somente à mudança no clima que é atribuída, direta ou indiretamente, à atividade humana, que altera a composição da atmosfera e a variabilidade climática.

3 Como, por exemplo, mudanças nos regimes de chuvas e ventos, com intensificação de fenômenos naturais como furacões, ciclones e inundações.

4 A controvérsia reside no fato de não se saber, com precisão, até que ponto a interferência humana afeta o sistema climático, pois a mudança climática é um fato histórico já ocorrido antes na história do Planeta e que gerou eras glaciais.

5 Adaptado do termo Anthropogenic emissions, que significa emissões dos gases do "efeito estufa" por atividades humanas. Essas emissões decorrem principalmente da queima de combustíveis fósseis para produção de energia, desmatamento e uso da terra. 
(PFCs). A presença desses gases permite que a atmosfera capte radiação solar e retenha uma parte do calor, como se fosse uma estufa, o que proporciona condições adequadas para a vida na Terra.

Entretanto, o homem, por meio da atividade econômica, também gera alguns desses gases, sendo o mais importante o dióxido de carbono $\left(\mathrm{CO}_{2}\right)$. Este gás surge da queima de qualquer material que contenha o elemento carbono e, portanto, pode-se encontrá-lo na queima de combustíveis fósseis como carvão, petróleo e gás natural, e nas atividades econômicas carbo-intensivas como as de metalurgia, siderurgia e transportes. Além do $\mathrm{CO}_{2}$, pode-se destacar o metano $\left(\mathrm{CH}_{4}\right)$ que é liberado pela decomposição de matéria orgânica. Neste caso, as atividades econômicas como agricultura, desmatamento e produção de lixo e esgoto são as maiores fontes geradoras de metano.

\subsection{O Protocolo de Quioto e a participação brasileira}

A preocupação da humanidade com as emissões dos gases do efeito estufa e as possíveis conseqüências do aquecimento global fizeram com que os organismos supranacionais tomassem providências para combater esse problema. Pode-se dizer que o processo que culminou no documento chamado "Protocolo de Quioto" começou em junho de 1988, em Toronto (Canadá), na Conferência Mundial sobre Mudanças Atmosféricas, como resultado da necessidade de adoção de uma convenção internacional sobre a mudança climática. Nessa conferência foi criado um grupo de trabalho para dar respaldo técnico e científico, constituído por vários países e profissionais de várias áreas do conhecimento, chamado de Painel Intergovernamental sobre a Mudança Climática - IPCC (sigla em inglês para Intergovernmental Panel on Climate Change). ${ }^{6}$

Dois anos após o primeiro relatório desse grupo, que concluiu que a mudança climática representaria de fato uma ameaça para a humanidade, foi criada a Convenção da Organização das Nações Unidas (ONU) sobre a mudança do clima. ${ }^{7}$ O objetivo principal dessa Convenção era estabilizar as emissões e, conseqüentemente, as concentrações de gases do efeito estufa na atmosfera num nível que impediria que a interferência antrópica danificasse o sistema climático. Era também objetivo dessa convenção que a produção de alimentos não fosse ameaçada, e permitir que o crescimento econômico prosseguisse de maneira sustentável. Como resultado, ficou acordado, em seu Anexo I, que os países da OCDE e antiga URSS adotariam políticas de mitigação capazes de fazer com que os níveis de emissão antrópica dos referidos gases retornassem aos níveis de 1990 até o ano 2000 (primeiro prazo). Em 1997, em Quioto, no Japão, foi aprovado o documento (que veio a ser chamado Protocolo de Quioto) quantificando as metas de redução de emissões. ${ }^{8}$

Em um primeiro período, essas metas deveriam ser atingidas entre 2008 e 2012 pelos países constantes em seu Anexo B (praticamente os mesmos do Anexo I da Convenção da ONU). ${ }^{9}$ Os Estados Unidos, maior parceiro comercial da ALCA (responsável por cerca de $40 \%$ das emissões entre os países do Anexo I e aproximadamente um quarto do consumo mundial de energia relacionada às emissões de carbono em 1990), haviam concordado em reduzir 7\% de suas emissões comparadas

6 Organizado pelo Programa das Nações Unidas sobre Meio Ambiente (PNUMA) e pela Organização Meteorológica Mundial (OMM), o IPCC é hoje o principal responsável pelas previsões, amplamente divulgadas para o conhecimento geral, sobre aquecimento global nas próximas décadas.

7 A Segunda Conferência Mundial sobre o Clima, em 1990 (a primeira havia sido em 1978, em Genebra, na Suíça), estabeleceu a necessidade de um tratado, chamado inicialmente "Convenção-Quadro, sobre Mudanças Climáticas". As negociações começaram em dezembro do mesmo ano, sendo criado um comitê para produzi-lo - o Comitê Intergovernamental de Negociação para uma Convenção-Quadro sobre Mudanças Climáticas (Intergovernmental Negotiating Committee for a Framework Convention on Climate Change - INC/FCCC).

8 Pereira e May (2003) relatam que as metas de redução de carbono foram estabelecidas por meio de uma espécie de "leilão", em que os negociadores ofereciam suas metas.

9 A Convenção dividiu os países em dois grupos: os que seriam abrigados a reduzir suas emissões e foram listados em seu Anexo I (Partes/Países Anexo I), e os demais que não foram listados no referido Anexo (Partes/Países não-Anexo I). O Anexo B do Protocolo de Quioto é equivalente ao Anexo I, com pequenas alterações. 
aos níveis de 1990 até 2008/2012. (Protocolo de Quioto, 1997). ${ }^{10}$ Entretanto, posteriormente, em 2001, o presidente Bush retirou os Estados Unidos do Protocolo de Quioto. ${ }^{11}$ Para isso foram utilizados alguns argumentos: incerteza sobre os reais danos que as emissões trariam ao processo de mudança climática; afirmação de que os países pobres também deveriam fazer parte do tratado e serem forçados a reduzir emissões ao mesmo tempo em que os países ricos; e, principalmente, preocupação quanto aos danos que o acordo poderia trazer para o desempenho econômico americano.

$\mathrm{Na}$ verdade, o principal motivo de dissensão foi a proposta de um grupo de países conhecido como Grupo do Guarda-Chuva, formado principalmente por Estados Unidos, Canadá, Japão e Austrália, de incluir projetos florestais (como reflorestamentos) no cálculo das reduções de emissões de $\mathrm{CO}_{2}$. Isto aliviaria os EUA, atualmente o maior emissor de dióxido de carbono do mundo, de parte de sua responsabilidade de diminuir suas emissões previstas pelo Protocolo de Quioto. A proposta foi rejeitada pela União Européia, levando a um impasse. Entretanto, países do Grupo do Guarda-Chuva, como o Japão, decidiram ratificá-lo, o que afastou o medo de que esse impasse impedisse futuras negociações. ${ }^{12}$ Recentemente, com a ratificação da Rússia (final de 2004), que era responsável por cerca de $17 \%$ das emissões globais dos países industrializados em 1990, a condição mínima estabelecida para entrada em vigor do Protocolo foi atingida (comprometimento de redução 55\% das emissões totais). A vigência do referido acordo teve início em 16 de fevereiro de 2005.

Para ajudar a atingir essas metas de redução de emissões pelos países do Anexo I, o Protocolo de Quito estabeleceu ainda a possibilidade de utilização dos "mecanismos de flexibilidade". Para Pereira e May (2003), esses mecanismos representaram uma grande inovação trazida pelo Protocolo, pois pelo fato de a mudança climática se tratar de um fenômeno global, não importa onde ocorrem as reduções de emissões. Assim, esses mecanismos permitem que um país do Anexo I contabilize para si reduções de emissões em outros países, seja diretamente, ou via investimentos de projetos em outros países. O Protocolo de Quioto permitiu três possibilidades: comércio de emissões, implementação conjunta e mecanismos de desenvolvimento limpo.

O artigo 17 do Protocolo diz que os países integrantes do Anexo I podem participar de um mercado de comércio de emissões de forma a atingir seu comprometimento de redução de emissões. A idéia é que aqueles países que podem atingir rapidamente seu alvo de emissões, devido aos seus custos de abatimento menores, possam vender o excedente para países com altos custos de abatimento. Os outros dois instrumentos, implementação conjunta (IC) e mecanismos de desenvolvimento limpo (MDL), basicamente buscam o mesmo objetivo do comércio de emissões (alcançar a redução de emissões de maneira mais eficiente do ponto de vista econômico), mas com uma diferença importante: a transferência de tecnologia por meio de investimentos. A IC permite a um país patrocinar um projeto de redução de emissões em outro país do Anexo I, adquirindo assim o respectivo crédito dessa redução como se fosse dele próprio. O MDL é similar ao IC, mas com uma particularidade: os projetos só podem ser desenvolvidos em países não pertencentes ao chamado Anexo I. ${ }^{13}$

10 Ficou acertado na rodada de negociações de Bonn, em 2001, que o acordo vai contemplar mecanismos de sanções. Entretanto, esses mecanismos serão determinados, via emenda, depois da ratificação do Protocolo.

11 O governo de George W. Bush radicalizou a posição dos EUA ao contestar as bases científicas do Protocolo de Quioto, oportunidade em que chegou a convocar um grupo de cientistas norte-americanos para rever os resultados das pesquisas do IPCC.

12 O Brasil ratificou-o em 19 de junho de 2002.

13 Como definido no artigo 12 do Protocolo de Quioto, o MDL consiste na possibilidade de um país que tenha compromisso de redução (Anexo I) adquirir certificados de redução de emissões de gases de efeito estufa em projetos gerados em países em desenvolvimento, como forma de cumprir parte de seus compromissos. A idéia consiste em que um projeto gere certificados de reduções de emissões adicionais àquelas que ocorreriam na ausência do projeto, garantindo benefícios reais, mensuráveis e de longo prazo, para a mitigação da mudança do clima. 
O Brasil é um membro parte do Protocolo de Quioto, mas não como componente integrante do Anexo I. ${ }^{14} \mathrm{O}$ Brasil faz parte do grupo de países que emitem dióxido de carbono abaixo do nível máximo estabelecido pelo Protocolo e, portanto, não tem obrigação de reduzir seus níveis de emissão no prazo previsto pelo mesmo. ${ }^{15}$ Assim sendo, a participação brasileira nesse processo seria a de um receptor de investimentos dos países desenvolvidos, interessados em financiar projetos para redução de gases do efeito estufa. ${ }^{16}$

A posição oficial brasileira, divulgada em documento elaborado pela Coordenação de Pesquisa em Mudanças Globais do Ministério da Ciência e Tecnologia (MCT, 1999), era que o país não participasse desse processo apenas como um mero "conservador" de florestas. De acordo com o referido documento, essa prática não contribui para a mitigação da mudança do clima, uma vez que não há variação negativa na concentração de gases do efeito estufa na atmosfera no ato de preservar uma floresta da devastação. O MCT defendeu a criação de um fast track (via rápida), por meio da certificação de redução de emissões de gases do efeito estufa, cujos certificados conhecidos como CERs seriam comprados e mantidos em carteira por uma instituição financeira nacional. As maiores dúvidas da época em que foi editado esse documento pairavam sobre a existência de demanda futura para as CERs, incerteza quanto à elegibilidade dos projetos, ao custo da tonelada de carbono, e à entrada em vigor do Protocolo de Quioto.

A dúvida quanto a esse último empecilho foi dirimida em 16 de fevereiro de 2005, ocasião em que o Protocolo de Quioto entrou em vigor e passou a ser o Tratado de Quioto. Quanto ao mercado de CERs, foi anunciado pela imprensa que a Bolsa de Mercadorias \& Futuros $(\mathrm{BM} \& \mathrm{~F})$ juntamente com o Ministério do Desenvolvimento, Indústria e Comércio (MDIC) vão lançar o Mercado Brasileiro de Redução de Emissões (MBRE), que deverá entrar em funcionamento até o final de 2005 . $^{17}$

\section{Metodologia}

O instrumento utilizado aqui neste trabalho para implementar os experimentos é um modelo de Equilíbrio Geral Computável chamado GTAP-E. Este é uma versão modificada do GTAP (Global Trade Analysis Project) desenvolvido pela Universidade de Purdue no estado de Indiana/ EUA. Não é intenção descrever detalhadamente o modelo GTAP, pois sua teoria já está muito bem documentada em Hertel (1997). O GTAP-E (energia) foi projetado para analisar assuntos relacionados ao uso de energia e impactos de políticas de mudança climática. Ele difere do modelo GTAP padrão principalmente pelo aspecto particular da substituição entre combustíveis e entre combustível e demais fatores de produção.

Como o GTAP-E (Burniaux e Truong, 2002) é um modelo que pertence à família de modelos GTAP, ele possui a mesma estrutura teórica padrão (competição perfeita e retornos constantes de escala na produção), porém com uma estrutura de produção e consumo que inclui uma descrição

14 Sua adesão foi assinada pelo Presidente Fernando Henrique Cardoso em 2002.

15 Embora o Brasil já figure na sexta colocação, com 3\% das emissões dos gases do efeito estufa no período 1990/1994. Porém, não em decorrência da sua industrialização ou queima de combustíveis fósseis, mas sim pelo desmatamento que é responsável por $77 \%$ das emissões brasileiras (Revista Carta Capital de 15 de dezembro de 2004).

16 Seroa da Motta et al. (2000) destacam os setores florestal e de energia como potenciais para a implantação de projetos que visem a esse objetivo. Embora no setor de energia a eletricidade possa ser gerada predominantemente por hidrelétricas, os autores enfatizam que o crescimento econômico pode trazer importantes emissões de $\mathrm{CO}_{2}$, dadas as tendências normais de utilização dos combustíveis fósseis.

17 Mais informações sobre a mudança climática e o Protocolo de Quioto podem ser encontradas em Protocolo de Quioto (1997), MCT (1999) e Seroa da Motta et al. (2000). 
mais detalhada das possibilidades de substituição de uso entre as diferentes fontes de energia. ${ }^{18} \mathrm{O}$ GTAP-E utiliza uma base de dados que, além dos fluxos e parâmetros usualmente utilizados pelo GTAP padrão, incluem elasticidades de substituição para o uso das commodities energia e quantidades de emissões de $\mathrm{CO}_{2}$ gerados pela queima dos combustíveis fósseis como carvão, petróleo cru e gás natural, como também os produtos derivados do petróleo e geração de eletricidade.

\subsection{Fechamento (closure)}

O fechamento ou closure $^{19}$ macroeconômico utilizado neste modelo é chamando de neoclássico. ${ }^{20}$ Neoclássico porque, ao contrário dos fechamentos não-neoclássicos que consideram o investimento fixo, este permite o investimento se ajustar a variações na poupança. Os fatores de produção que têm mobilidade entre os setores são capital, mão-de-obra qualificada e não-qualificada. $\mathrm{O}$ grau de mobilidade dos fatores de produção é governado por uma elasticidade de transformação constante. Terra e recursos naturais são os fatores de produção imóveis.

Neste trabalho foram utilizados dois closures, um para cada simulação. A diferença entre eles reside unicamente no fato de que, quando é simulada a redução de emissões de $\mathrm{CO}_{2}$ e o comércio de emissões entre as regiões, o closure precisa ser adequado à nova situação. As restrições quantitativas das emissões de $\mathrm{CO}_{2}$ são praticadas tornando-se endógena a variável de taxação real sobre o carbono (imposto nominal deflacionado pelo deflator do PNB) e exógena a taxa de crescimento das emissões de $\mathrm{CO}_{2}$. Este procedimento permite que seja dado um choque na variável exógena com a restrição de emissões que se pretende impor. Este arranjo permite que sejam simuladas as restrições de emissões que foram acordadas pelo Protocolo de Quioto.

Para estabelecer o comércio de emissões foi necessário, primeiramente, identificar o grupo de países/regiões aos quais as restrições serão impostas. Estabelecido este grupo, a próxima etapa prevê que a restrição global de emissões seja igual à soma das restrições individuais dos mesmos. Ou seja, deve-se atentar para que a soma das quotas individuais dos países/regiões, exógenas para este caso, fique consistente com a restrição total de emissões para que se evite desequilíbrio de fluxos de comércio. Nesse sentido, a variável que representa o crescimento das emissões totais deve tornar-se exógena e assumir o valor da restrição total, ao mesmo tempo que a variável que representa o custo marginal do abatimento correspondente ao grupo como um todo deverá ficar endógena.

É preciso ainda providenciar para que a compra de direitos para emissões seja compensada por um correspondente aumento nas exportações de bens e serviços (ou vice-versa). Esta é uma condição necessária para satisfazer a exigência do modelo original GTAP de que os fluxos líquidos de capital com o resto do mundo sejam constantes. Em outras palavras, o fluxo de capital em cada país/região permanece constante e igual ao seu valor de benchmark de maneira que quaisquer fluxos associados ao comércio de emissões sejam compensados por um correspondente fluxo nas transações correntes. Isto é feito estabelecendo-se que as variações no saldo das transações correntes, incluindo comércio de permissão de emissões, sejam exógenas e iguais a zero para todas as regiões (exceto uma).

18 As principais mudanças nessas estruturas estão ilustradas no Anexo A deste artigo.

19 O closure de um cenário pode ser considerado como uma maneira especial de escolha das variáveis endógenas e exógenas do modelo. Para que a resolução do modelo chegue a uma solução, é necessário que o número de equações seja igual ao número de variáveis endógenas. Como o número de variáveis geralmente é superior ao número de equações, devem ser selecionadas algumas variáveis para serem exógenas ao modelo (fixas).

20 O termo "closure" macroeconômico foi utilizado por Sen (1963) para definir uma situação na qual não existe mecanismo intertemporal para definir o investimento, ou seja, o modelo precisa ser "fechado" em determinado ponto do tempo. 


\subsection{Agregação}

Algumas adequações se fizeram necessárias na base original do GTAP (dados oferecidos pela versão 5.4). Como o Software GTAPAgg utilizado para agregação dessa base de dados não gerou todos os coeficientes necessários para a implementação da mesma no GTAP-E, este trabalho teve de ser feito separadamente. Para que a base de dados se tornasse compatível com os dados requeridos pela teoria do modelo GTAP-E foram criados 24 novos coeficientes a partir dos dados originais. Com exceção dos dados de emissão de $\mathrm{CO}_{2}$, que foram obtidos no trabalho de Lee (2003), as outras adequações foram modificações nas dimensões e nomenclatura dos conjuntos do modelo GTAP-E.

A agregação regional utilizada neste trabalho foi desenhada para possibilitar uma avaliação integrada de um possível acordo comercial da ALCA e as emissões de $\mathrm{CO}_{2}$ tratadas pelo Protocolo de Quioto. ${ }^{21}$ Foram agrupados 78 países da versão 5.4 da base de dados do GTAP em 10 novas regiões (Quadro 1). ${ }^{22}$ As mesmas foram agrupadas de modo a privilegiar a análise dos resultados dos principais países envolvidos no acordo da ALCA como o Brasil, Estados Unidos, Canadá e México, Resto do Mercosul e Resto da ALCA, assim como possibilitar a construção de cenários para implementação do Protocolo de Quioto quanto aos seus principais atores, que são os países integrantes do chamado Anexo I (EUA, Canadá, EU e OANEX1), e outros países que são considerados grandes emissores de $\mathrm{CO}_{2}$ por meio da queima de combustíveis fósseis como China e Índia, por exemplo.

O critério para agregação setorial restringiu-se principalmente às disponibilidades dos dados de emissões de $\mathrm{CO}_{2}$ compatíveis com o modelo GTAP-E. Assim sendo, foram agrupadas 57 indústrias em oito novos setores, cinco deles em commodities de energia (carvão, petróleo cru, gás natural, derivados de petróleo e carvão e eletricidade) e três outros grandes setores (agricultura, indústrias intensivas em energia e outras indústrias e serviços). Esta agregação nos permitirá concentrar a análise principalmente nos setores mais emissores de $\mathrm{CO}_{2}$.

\section{DESCRIÇÃO DOS CENÁRIOS E RESULTADOS}

Para atingir o objetivo ao qual se propõe este trabalho, ou seja, uma avaliação conjunta da implementação da ALCA juntamente com o protocolo de Quioto, simularam-se dois cenários. $\mathrm{O}$ primeiro refere-se à consolidação da ALCA por meio da eliminação das barreiras tarifárias. O segundo, além dos choques impostos ao primeiro experimento, têm-se os de redução de emissões preconizados pelo Protocolo de Quioto. A construção desses cenários objetiva fazer uma comparação de duas situações para a implementação da ALCA a fim de se avaliar os ganhos (perdas) em termos econômicos e ambientais de ambas as situações.

21 A Tabela A.1 no Anexo B ilustra a utilização de energia (antes das simulações) pelos setores do modelo no Brasil e demais regiões que irão compor a ALCA.

22 O GTAP 5.4 Interim Release foi disponibilizado para quem comprou a versão 6.0 da base de dados que está sendo construída. A versão 5.4 foi construída com base no GTAP 5.0 e tem o mesmo ano de referência deste (1997). Entretanto, na versão 5.4 foram desagregadas mais 14 regiões, com cinco atualizações e outras revisões para a base anterior. 
Quadro 1 - Agregação utilizada

\begin{tabular}{|c|c|}
\hline Agregação regional & Agregação setorial \\
\hline $\begin{array}{l}\text { 1. Brasil } \\
\text { 2. Estados Unidos (EUA) } \\
\text { 3. México } \\
\text { 4.Canadá } \\
\text { 5. Resto do Mercosul (RMERC)* } \\
\text { Argentina e Uruguai. } \\
\text { 6. Resto da ALCA (RALCA) } \\
\text { América Central, Caribe, } \\
\text { Colômbia, Peru, Venezuela, Resto do Pacto Andino, } \\
\text { Chile, Resto da América do Sul. } \\
\text { 7. União Européia (UE) } \\
\text { Áustria, Bélgica, Dinamarca, Finlândia, França, } \\
\text { Alemanha, Reino Unido, Grécia, Irlanda, Itália, } \\
\text { Luxemburgo, Holanda, Portugal, Espanha e Suécia. } \\
\text { 8. Outros países do Anexo } 1 \text { (OANEX1) } \\
\text { Austrália, Nova Zelândia, Japão, Suíça, Resto da } \\
\text { Área de Livre-comércio da Europa, Bulgária, Croácia, } \\
\text { República Tcheca, Hungria, Polônia, Romênia, } \\
\text { Eslováquia, Eslovênia, Estônia, Letônia, Lituânia, } \\
\text { Rússia. } \\
\text { 9. Outros grandes emissores (OGEMISS) } \\
\text { China, Coréia, Taiwan, Indonésia, Malásia, Cingapura, } \\
\text { Tailândia, Vietnam, Índia, Resto da Antiga União } \\
\text { Soviética, Resto do Oriente Médio, Resto da África } \\
\text { do Norte, Resto da União Aduaneira da África do Sul, } \\
\text { Resto da África Subsaariana. } \\
\text { 10. Resto do Mundo (ROW) } \\
\text { Hong Kong, Filipinas, Bangladesh, Siri Lanka, } \\
\text { Resto da Ásia do Sul, Albânia, Malta, Chipre, } \\
\text { Turquia, Marrocos, Botsuana, Malawi, Moçambique, } \\
\text { Tanzânia, Zâmbia, Zimbábue, Outros da África do } \\
\text { Sul, Uganda, Resto do Mundo. }\end{array}$ & $\begin{array}{l}\text { 1. Agropecuária } \\
\text { Agricultura primária, atividade florestal, pesca, arroz com casca, } \\
\text { trigo, outros cereais em grão, vegetais, frutas, noz, sementes de óleo } \\
\text { (azeite), açúcar de cana, açúcar de beterraba, fibras à base de plantas, } \\
\text { outras colheitas, bovinos, ovinos, caprinos, eqüinos, outros produtos } \\
\text { animais, leite não-processado, lã, bicho-da-seda. } \\
\text { 2. Carvão } \\
\text { Mineração e aglomeração de carvão duro, carvão fóssil e turfa. } \\
\text { 3. Petróleo cru } \\
\text { Extração de petróleo bruto. } \\
\text { 4. Gás natural } \\
\text { Extração de gás natural, manufatura e distribuição. } \\
\text { 5. Derivados de Petróleo e carvão } \\
\text { Produtos derivados do petróleo, carvão e processamento de } \\
\text { combustível nuclear. } \\
\text { 6. Eletricidade } \\
\text { Produção, transmissão e distribuição. } \\
\text { 7. Indústrias intensivas em energia } \\
\text { Outros minerais, produtos químicos básicos, outros produtos químicos, } \\
\text { produtos de plástico e borracha, outros produtos minerais, metais } \\
\text { ferrosos, outros metais. } \\
\text { 8. Outras indústrias e serviços } \\
\text { Carne (bovina, caprina, eqüina), outros produtos de carne, gorduras } \\
\text { e óleos vegetais, produtos diários, arroz processado, açúcar, outros } \\
\text { produtos alimentícios, bebidas e tabaco, têxteis, vestuário, produtos de } \\
\text { couro, produtos de madeira, produtos de papel, publicações, produtos } \\
\text { de metal, veículos e suas partes, outros equipamentos de transporte, } \\
\text { equipamento eletrônico, outras máquinas e equipamentos, outras } \\
\text { manufaturas, água, construção, comércio, transporte, comunicação, } \\
\text { serviços financeiros, seguros, negócios, recreação, administração } \\
\text { pública e defesa, saúde, aluguéis. }\end{array}$ \\
\hline
\end{tabular}

Fonte: Base de dados do GTAP versão 5.4.

* A base de dados do GTAP não contempla o Paraguai.

\subsection{ALCA - eliminação de tarifas de importação e exportação}

O Brasil participou, em 1994, da chamada Primeira Cúpula das Américas, quando ocorreram as negociações para a formação da Área de Livre Comércio das Américas (ALCA). A ALCA tem como objetivo constituir uma zona com livre trânsito de bens e serviços. Entretanto, para que isso seja possível, conforme as regras da Organização Mundial do Comércio (OMC), é preciso que sejam eliminadas as tarifas de comércio (importação e exportação) de $85 \%$ dos produtos e serviços negociados entre os países participantes do bloco (todos do continente americano, exceto Cuba), em no máximo quinze anos. Programada para entrar em funcionamento no final de 2005, com o fim das negociações para as reduções de tarifas, a implementação da ALCA tem encontrado resis- 
tências. Pelo lado das economias em desenvolvimento, entre as quais se encontra o Brasil, teme-se a ruína de parques industriais fracos e pouco desenvolvidos. Assim, o Brasil defende uma abertura gradual, e também que as negociações sejam feitas no âmbito do MERCOSUL, como forma de ganhar força para negociar com os Estados Unidos. ${ }^{23}$

A simulação desse cenário consistiu na completa remoção de tarifas de exportação e importação entre os países que integram a Área de Livre-comércio das Américas - ALCA. De acordo com Domingues (2002), pode-se supor que, dado o cronograma de implementação da ALCA, a primeira etapa recaia sobre a eliminação das tarifas intrabloco.

\section{Impactos Econômicos}

Antes de se partir para a análise dos resultados, cabe fazer um breve comentário sobre o que vem a ser bem-estar e sua decomposição no contexto deste trabalho. A fonte de variação de bemestar gerada no GTAP é resultado, por exemplo, da retirada ou imposição de distorções (impostos, subsídios e taxas) ou então devido a variações na condição tecnológica de determinado mercado em dada região. ${ }^{24}$ A Variação Equivalente (EV) associada com uma perturbação no modelo GTAP (medida utilizada como proxy para o bem-estar econômico) é igual à diferença entre a despesa requerida para obter o novo nível de utilidade (após a simulação) aos preços iniciais ( $\left.\mathrm{Y}_{\mathrm{EV}}\right)$ e o nível de utilidade disponível no equilíbrio inicial (Y), ou seja, $\mathrm{EV}=\mathrm{Y}_{\mathrm{EV}}-\mathrm{Y}$. (McDougall, 2001). Essa medida pode ser decomposta em três componentes: efeitos alocativos, termos de troca, e o saldo investimento-poupança.

Os efeitos alocativos, no contexto dessa simulação, mostram que uma parcela da EV proveniente dos ganhos (ou perdas) de eficiência é ocasionada pela remoção (inclusão) das distorções causada pela incidência de tarifas sobre o comércio. Produtos importados mais baratos, por exemplo, provocam ganhos tanto por meio do consumo ampliado como na forma como os recursos produtivos domésticos são aplicados. Os termos de troca são afetados pela variação dos preços das exportações referente ao corte das tarifas. Neste modelo, a variação nos termos de troca é dada pela diferença entre as variações porcentuais dos índices de preço recebido e pago pelos tradables produzidos e usados, respectivamente, em determinada região. O impacto do componente investimentopoupança (I-S) sobre o bem-estar, por sua vez, é função dos preços da poupança e investimento e da situação como determinada região aparece no saldo de poupança líquida.

A Tabela 1 mostra a variação equivalente da renda e sua decomposição sofrida por ocasião da simulação. Apesar de os resultados apresentados a seguir serem em valores absolutos, eles fornecem uma boa idéia de ganhos (perdas) de bem-estar que as regiões obteriam em razão deste experimento. Com exceção do Canadá, que perdeu com a formação da ALCA, e o RMER (Resto do MERCOSUL) que ficou praticamente estagnado, pode-se observar que ganhariam com o acordo todas as regiões participantes da formação do bloco. A redução do bem-estar no Canadá foi ocasionado pela perda nos termos de troca que, por sua vez, deveu-se à redução no preço das commodities exportadas. Essa queda no preço das exportações é uma forma de compensar o aumento das importações ocasionadas pela redução de tarifas e, assim, manter o equilíbrio da balança comercial. Pode-se argumentar que a melhora no bem-estar nos países da ALCA deu-se basicamente em detrimento das regiões que não participaram do bloco, pois as mesmas não sofreram choques de eliminação de tarifas e, portanto, não se favoreceram dos seus efeitos. ${ }^{25}$ A queda nos termos de

23 Para uma análise mais detalhada do processo de integração da ALCA, ver Bouzas (2001) e Baumann (2003).

24 O tamanho do ganho associado à retirada dessa distorção é uma função do tamanho da distorção inicial, da magnitude dessa variação, e da sensibilidade de resposta do mercado atingido por tal mudança.

25 A questão do desvio e criação de comércio com a ALCA pode ser analisada de forma mais detalhada em Azevedo (2003). 
troca observada para esses últimos, principalmente na União Européia, pode ser creditada também à queda no preço das exportações.

Os Estados Unidos foram os maiores beneficiados, alcançando um ganho de bem-estar econômico avaliado em US $\$ 4,8$ bilhões. Este resultado foi proporcionado principalmente pelos ganhos dos termos de troca, que foram responsáveis por praticamente três quartos desse total. Essa melhoria nos termos de troca, segundo Panagariya (1997), é uma possibilidade que surge quando países com tarifas baixas formam um bloco comercial com outros de tarifas elevadas, uma vez que ocorre uma transferência líquida de receita das tarifas desses últimos para os primeiros. No Brasil, o principal mecanismo de ganho proveniente da formação do bloco foi o de eficiência alocativa (US\$ 1.315 milhões). O montante de EV alcançado por meio desse canal mais que compensou a perda nos termos de troca de US\$25 milhões, gerando o ganho de bem-estar de U\$1,4 bilhão. O efeito I-S de US\$ 140 milhões revela o Brasil, nesta simulação, como sendo um supridor líquido de poupança.

Tabela 1 - Variação do bem-estar e sua decomposição - US \$ milhões

\begin{tabular}{lrrrr}
\hline Regiões & \multicolumn{1}{c}{ EV } & Alocativo & Termos de troca & I-S \\
\hline Brasil & 1429,63 & 1315,4 & $-25,69$ & 139,92 \\
EUA & 4848,66 & 885,37 & 3590,12 & 373,17 \\
México & 430,71 & 166,25 & 327,41 & $-62,95$ \\
Canadá & $-221,24$ & 82,36 & $-267,36$ & $-36,25$ \\
RMERC & $-2,89$ & 5,06 & 12,27 & $-20,22$ \\
RALCA & 3534,5 & 2231,37 & 1389,7 & $-86,57$ \\
UE & $-3667,81$ & $-1258,03$ & $-2359,25$ & $-50,53$ \\
OANEX1 & $-2294,61$ & $-651,36$ & $-1597,1$ & $-46,16$ \\
OGEMISS & $-1431,26$ & $-340,04$ & $-966,94$ & $-124,28$ \\
ROW & $-249,58$ & $-42,24$ & $-120,28$ & $-87,06$ \\
\hline
\end{tabular}

Fonte: Valores resultantes da simulação do cenário ALCA.

Os setores responsáveis pelas perdas nos termos de troca no Brasil foram os de produtos agropecuários e outras indústrias e serviços (US\$ 214 e US $\$ 76$ milhões, respectivamente na Tabela 2). Este resultado foi uma conseqüência natural da eliminação de tarifas, ou seja, queda dos preços nos mercados dos produtos gerados pela desgravação tributária (13,8\% nos EUA e 6,7\% no RALCA, para o setor agropecuário) que, não por coincidência, tiveram as maiores reduções tarifárias médias nesse setor $\left(6,7 \%\right.$ e $10,7 \%$, respectivamente) ${ }^{26}$

O mesmo raciocínio - ou seja, a redução tarifária com conseqüente redução do preço dos bens importados - pode ser utilizado para justificar os ganhos de eficiência provocados pela melhor alocação dos recursos. Os setores mais beneficiados no Brasil por este critério foram outras indústrias e serviços (US $\$ 1,1$ bilhão), produtos derivados de petróleo e carvão (US $\$ 110$ milhões) e indústrias intensivas em energia (US\$ 83 milhões).

26 Esses dados refletem a estrutura tarifária vigente antes dos choques de eliminação de tarifas e podem ser conferidos em Feijó (2005). 
Tabela 2 - Decomposição do bem-estar no Brasil por setor - US \$ milhões

\begin{tabular}{lcc}
\hline Setores & Efeito alocativo & Termos de troca \\
\hline Agropecuário & 18,68 & $-214,07$ \\
Carvão & 0,44 & 1,96 \\
Petróleo cru & 1,2 & 26,31 \\
Gás natural & $-0,02$ & 0,00 \\
Derivados P\&C & 110,46 & 3,24 \\
Eletricidade & $-1,36$ & 21,34 \\
Ind.Int.Energia & 83,5 & 211,85 \\
Out. Ind. e Serv. & 1102,51 & $-76,31$ \\
\hline Total & 1315,4 & $-25,67$ \\
\hline
\end{tabular}

Fonte: Valores resultantes da simulação do cenário ALCA.

A Tabela 3 ilustra a variação do produto total e dos setores do modelo em razão desta simulação. Em termos de crescimento do produto (PIB), os maiores ganhadores dentro do bloco foram, respectivamente, RALCA $(0,49 \%)$ e Brasil $(0,17 \%) .{ }^{27} \mathrm{O}$ resultado de crescimento do PIB brasileiro neste trabalho ficou próximo dos 0,21\% encontrado por Domingues (2002) e dos 0,30\%, por Pereira (2001), que utilizaram os modelos SPARTA (São Paulo Applied Regional Trade Analysis) e GTAP, respectivamente, para avaliar os impactos da ALCA. ${ }^{28}$

Tabela 3 - Produto total e por setor na ALCA (variação \%)

\begin{tabular}{lccrrrr}
\hline & Brasil & EUA & México & Canadá & RMERC & RALCA \\
\hline PIB (qgdp) & $\mathbf{0 , 1 7}$ & $\mathbf{0 , 0 1}$ & $\mathbf{0 , 0 4}$ & $\mathbf{0 , 0 1}$ & $\mathbf{0}$ & $\mathbf{0 , 4 9}$ \\
Agropecuário & 0,12 & $-0,41$ & $-0,33$ & $-0,32$ & 0,24 & 0,17 \\
Carvão & $-1,11$ & $-0,13$ & $-0,03$ & 0,44 & $-0,18$ & $-6,12$ \\
Petróleo cru & $-2,29$ & $-0,1$ & $-0,3$ & 0,17 & 3,13 & $-2,67$ \\
Gás natural & $-0,12$ & $-0,18$ & $-0,18$ & 0,25 & 1,12 & $-2,77$ \\
Derivados P\&C & 1,57 & $-0,18$ & $-0,37$ & $-0,96$ & $-2,94$ & 11,24 \\
Eletricidade & $-0,26$ & $-0,06$ & 0,12 & 0,03 & 0,19 & $-1,4$ \\
Ind. Int. Energia & $-0,01$ & $-0,01$ & 0,35 & $-0,03$ & $-0,18$ & $-1,38$ \\
Out. Ind. e Serv. & 0,04 & 0,01 & 0,05 & 0,01 & $-0,08$ & 0,55 \\
CGDS & 1,73 & 0,12 & 0,55 & $-0,16$ & 0,56 & 6,78 \\
\hline
\end{tabular}

Fonte: Valores resultantes da simulação do cenário ALCA.

Cabe ressaltar que estes valores abaixo de $1 \%$ são resultados comuns em simulações com modelos baseados em uma estrutura de mercado em que prevalece a competição perfeita (primeira geração). ${ }^{29}$ Azevedo (2003) afirma que nestes modelos somente os ganhos estáticos associados a uma melhor alocação dos recursos e melhorias dos termos de troca são levados em consideração.

27 Como proxy para este indicador foi utilizado o índice de quantidade do PIB $(q g d p)$.

28 O modelo SPARTA é um modelo inter-regional de equilíbrio geral computável desenvolvido para avaliar a economia paulista. O mesmo foi desenvolvido a partir da estrutura teórica do modelo B-MARIA (Brasilian Multisectorial And Reional/Interregional Analysis) de Haddad e Hewings (1997).

29 Baldwin e Venables (1995) dividem a análise baseada em modelos de equilíbrio geral computável em três gerações conforme seus efeitos. A primeira fase se baseia em uma estrutura de mercado em que prevalece a competição perfeita onde ganhos dinâmicos não são considerados. Nestes modelos somente ganhos estáticos associados com uma melhor alocação de recursos e melhorias nos termos de troca têm lugar. A segunda fase compreende avaliações baseadas em modelos de competição imperfeita em que economias de escala e diferenciação de produto apresentam um papel relevante em determinados setores industriais. A terceira fase introduz os efeitos da integração nos níveis de poupança, investimento e crescimento econômico. 
Ao contrário, modelos com competição imperfeita (segunda geração) e modelos dinâmicos (terceira geração) tendem a apresentar magnitudes maiores como resultado de experimentos de políticas comerciais.

Analisando-se os setores isoladamente, observa-se que a produção brasileira se expandiu nos setores agropecuário, derivados de petróleo e carvão, outras indústrias e serviços e no setor de bens de capital (CGDS).$^{30}$ Dos cinco setores afetados negativamente, chama a atenção o fato de que quatro deles referem-se aos chamados setores de energia. Este mesmo padrão pode ser observado para a região RALCA, ressaltando-se, neste caso, o fenomenal crescimento do setor de derivados de petróleo e carvão $(11,24 \%)$. A queda de produção mais expressiva nos EUA ocorreu no setor agropecuário $(0,41 \%)$. Isto reflete, em grande medida, a queda da proteção tarifária que esse setor vinha obtendo antes da formação do bloco, simulada por este experimento. Cabe ressaltar também o desempenho negativo dos setores agropecuário $(0,32 \%)$ e de derivados de petróleo e carvão $(0,96 \%)$ no Canadá. Estes setores fizeram desse país o único com crescimento negativo dentro do bloco. Este fato pode ser justificado em certa medida pela perda de mercado desse país, que anteriormente era garantido pelo NAFTA (bloco comercial formada por EUA, México e Canadá).

\section{Impactos ambientais}

$\mathrm{O}$ aumento (redução) de emissões de $\mathrm{CO}_{2}$ gerado neste modelo e nesta simulação deu-se basicamente pelo aumento (redução) da atividade econômica dos setores do modelo e o associado uso das commodities de energia (carvão, petróleo, derivados de petróleo e carvão, gás natural e eletricidade). Portanto, nesta simulação, em que as mudanças exógenas foram geradas somente via choques nas tarifas de importação e exportação, o aumento (redução) de emissões ocorrerá se os setores mais poluidores apresentarem crescimento (contração) em sua atividade em decorrência direta ou indireta (por meio da sua utilização como insumo por setores não-poluidores) da liberalização comercial. (Fritz et al., 1998).

A Tabela 4 ilustra a variação nas emissões para as regiões do modelo. De maneira geral, o acordo comercial produziu um aumento na emissão de $\mathrm{CO}_{2}$ no âmbito da ALCA. No Brasil $(1,6 \%)$ e no RALCA (2\%) ocorreram os aumentos mais expressivos. As commodities que mais contribuíram para esse aumento foram petróleo cru (2,1\% e 4,5\%), derivados de petróleo (1,9\% e 3,8\%) e carvão $(0,8 \%$ e $0,7 \%)$, respectivamente para Brasil e RALCA. A redução de $\mathrm{CO}_{2}$ ficou por conta do RMERC (Argentina) por causa da diminuição das emissões oriundas do petróleo bruto e seus derivados $(-2,8 \%$ e $-1,2 \%$, respectivamente).

Um resultado interessante a ser investigado mais profundamente é o porquê da redução da emissão da commodity petróleo bruto se a produção desse produto aumentou 3,1\% nessa região, conforme foi mostrado na Tabela $3 .^{31}$ A resposta deve-se ao fato de que um aumento do preço desse produto no mercado interno, ocasionado pela mudança tarifária do experimento, fez com que a utilização desse insumo se reduzisse no setor produtor de derivados de petróleo (Derivados $\mathrm{P} \& \mathrm{C})$ mais que proporcionalmente ao aumento da sua produção, produção esta que foi direcionada principalmente para o Brasil e RALCA onde houve queda nos preços desse produto. ${ }^{32}$ Isto explica, em certa medida, o crescimento das emissões de $\mathrm{CO}_{2}$ dessas últimas regiões no setor de petróleo e derivados.

30 Cabe chamar a atenção que a agregação utilizada para os setores neste trabalho não privilegia a análise para os produtos mais importantes na pauta de exportações dos países da ALCA. Entretanto, como o objetivo principal do mesmo é avaliar os impactos decorrentes das políticas a mbientais (redução de $\mathrm{CO}_{2}$ ) sobre a economia e vice-versa, a agregação utilizada é a adequada.

31 Esta é uma das vantagens dos modelos de equilíbrio geral sobre os de equilíbrio parcial, visto que é possível analisar a interação entre vários mercados em várias regiões.

32 Os dados referentes a esses resultados podem ser encontrados em Feijó (2005). 
Tabela 4 - Emissões totais e por commodity de energia (variação \%)

\begin{tabular}{lcccccc}
\hline & Total & Carvão & Petróleo cru & Gás natural & $\begin{array}{c}\text { Derivados } \\
\text { P\&C }\end{array}$ & Eletricidade \\
\hline Regiões & & & & & & \\
\hline EUAil & 1,62 & 0,83 & 2,12 & $-0,11$ & 1,90 & $-0,11$ \\
México & 0,10 & $-0,03$ & $-0,12$ & $-0,06$ & 0,32 & $-0,04$ \\
Canadá & 0,30 & 0,14 & $-0,02$ & $-0,12$ & 0,44 & 0,12 \\
RMERC & 0,01 & $-0,01$ & $-0,15$ & 0,02 & 0,01 & $-0,06$ \\
RALCA & $-0,40$ & 0,05 & $-2,76$ & 0,35 & $-1,25$ & $-0,09$ \\
UE & 2,03 & 0,67 & 4,51 & $-2,29$ & 3,78 & $-0,24$ \\
OANEX1 & $-0,09$ & $-0,05$ & $-0,16$ & 0,03 & $-0,17$ & 0,00 \\
OGEMISS & $-0,04$ & 0,03 & $-0,20$ & 0,03 & $-0,14$ & 0,00 \\
ROW & $-0,02$ & 0,04 & $-0,19$ & 0,04 & $-0,14$ & 0,00 \\
\hline
\end{tabular}

Fonte: Valores resultantes da simulação do cenário ALCA.

Como se observou por meio da simulação desse cenário, obtiveram-se resultados sensivelmente melhores do ponto de vista econômico para a maioria das regiões envolvidas com a ALCA. No contexto ambiental, os resultados apontam para o aumento das emissões de $\mathrm{CO}_{2}$ em conseqüência do aumento da atividade econômica e a conseqüente maior utilização de energia. Entretanto, nos resultados obtidos pela presente simulação não estão considerados os choques exógenos de redução de $\mathrm{CO}_{2}$ que uma eventual implementação simultânea do Protocolo de Quioto traria aos resultados. A imposição de choques dessa natureza pode afetar os preços relativos das commodities, cuja utilização queima mais carbono, e assim alterar os fluxos comerciais. Esta possibilidade será investigada de forma mais detalhada a seguir.

\subsection{Alca1 - ALCA com Protocolo de Quioto e Comércio de Emissões entre todas as regióes do modelo}

Neste cenário proposto estão representadas, além da completa remoção das tarifas de exportação e importação no âmbito interno da ALCA (cenário Alca), a plena implementação do Protocolo de Quioto com o uso do mecanismo de flexibilidade "comércio de emissões" entre todas as regiões do modelo. A questão do Protocolo de Quioto foi simulada com duas simplificações que podem trazer interessantes projeções de possibilidades para o Brasil e os demais países da ALCA. ${ }^{33}$ A primeira é que os Estados Unidos concordariam em reduzir suas emissões. ${ }^{34}$ A segunda é que existiria um comércio mundial de emissões no qual é permitida a participação de todas as regiões do modelo. ${ }^{35}$ Esta alternativa vem servir como uma proxy da participação dos países em desenvolvimento nos mecanismos de flexibilidade do Protocolo de Quioto.

As restrições de emissões utilizadas aqui foram estimativas das restrições que teriam que ser impostas em 1997 (ano da base de dados da versão 5.4 do GTAP) para que os integrantes do Anexo

33 O Protocolo de Quioto limitou as emissões de um grupo de países conhecidos como “países do Anexo I" em torno de 5\% abaixo de seus níveis de 1990, meta a ser alcançada entre 2008 e 2012. (Protocolo de Quioto, 1997).

34 Os Estados Unidos, maior parceiro comercial da ALCA, responsável por cerca de $40 \%$ das emissões entre os países do Anexo I e aproximadamente um quarto do consumo mundial de energia relacionada às emissões de carbono em 1990, havia concordado em reduzir em 7\% dos níveis de 1990 até 2008/2012. (Protocolo de Quioto, 1997).

35 No texto original do Protocolo, o comércio de emissões é restrito somente aos países que compõem o chamado Anexo I. A participação de países não integrantes do Anexo I é feita por meio dos Mecanismos de Desenvolvimento Limpos (MDL). 
I do Protocolo de Quioto atingissem a meta proposta pelo mesmo, aliada ao fato de que a emissão nessas regiões aumentou entre 1990 e 1995, e que durante este período não houve contração de emissões. ${ }^{36}$ Tal argumento baseia-se no trabalho da OCDE (1999), o qual relata que existiu um gap de emissões entre a data de comprometimento do Protocolo e a data de confirmação do mesmo, ou seja, as emissões durante esse período de tempo aumentaram em muitos países. Esse aumento entre 1990 e 1995, segundo OCDE (1999), excedeu 10\% em países como Japão, Estados Unidos, Canadá e outros países da União Européia, como Dinamarca, Áustria, Bélgica e Holanda. Com base nestes fatos, as estimativas dos choques de redução de $\mathrm{CO}_{2}$ selecionados para este experimento foram de $-20 \%$ para as emissões nos EUA, OANEX1, Canadá, e $-15 \%$ na UE. ${ }^{37}$

\section{Impactos econômicos}

Comparando-se os ganhos de bem-estar econômico representados pela EV na Tabela 5 com os do experimento anterior (Tabela 1), observa-se que houve uma redução expressiva no ganho de todas as regiões do modelo. No Brasil, o resultado que era de US $\$ 1,4$ bilhão caiu para menos da metade (US $\$ 678$ milhões). No México houve até troca de sinal, ou seja, de um ganho de US\$ 431 milhões, este país da ALCA passa a amargar uma perda de bem-estar econômico no montante de US\$ 44 milhões. Analisando-se a decomposição do bem-estar do Brasil, os dados revelam que a perda de eficiência na alocação dos recursos foi a principal causa do menor ganho desta simulação (US $\$ 765$ milhões contra US\$1,3 bilhão da simulação anterior). Os termos de troca, a exemplo do que ocorreu na simulação anterior, também apresentaram perdas, embora em proporção bem maior (US\$209 milhões contra US\$26 milhões).

Tabela 5 - Variação do bem-estar e sua decomposição - US $\$$ milhões

\begin{tabular}{lrrrrr}
\hline Regiões & \multicolumn{1}{c}{ EV } & Alocativo & Termos de troca & CO $_{2}$ Trade* & I-S \\
\hline Brasil & 677,76 & 765,36 & $-209,32$ & 65,24 & 56,51 \\
EUA & 1477,42 & $-940,76$ & 5246,89 & $-3245,70$ & 414,88 \\
México & $-44,27$ & 42,28 & $-138,90$ & 98,38 & $-45,97$ \\
Canadá & $-1628,43$ & $-466,54$ & $-750,94$ & $-394,07$ & $-17,14$ \\
RMERC & $-306,02$ & $-189,21$ & $-154,28$ & 68,05 & $-30,55$ \\
RALCA & 1845,88 & 1434,25 & 422,22 & 170,19 & $-180,68$ \\
UE & $-4215,25$ & $-2677,10$ & 595,81 & $-2029,01$ & $-106,26$ \\
OANEX1 & $-9842,70$ & $-5235,25$ & $-1580,30$ & $-3007,61$ & $-21,49$ \\
OGEMISS & $-2882,30$ & $-7436,72$ & $-3293,53$ & 7943,63 & $-90,53$ \\
ROW & $-406,24$ & $-532,75$ & $-146,51$ & 252,44 & 20,74 \\
\hline
\end{tabular}

Fonte: Valores resultantes da simulação do cenário Alcal.

* Fluxos provenientes do comércio de emissões.

Os principais responsáveis pela redução da eficiência alocativa foram os setores de energia (principalmente derivados de petróleo e eletricidade). O ganho que era de US $\$ 1,3$ bilhão passou para US $\$ 796$ milhões (Tabelas 2 e 6). O imposto sobre carbono tem efeito similar e contrário ao efeito que teria a eliminação de uma tarifa de importação sobre a eficiência alocativa. Enquanto a remoção de uma tarifa de importação sobre determinado insumo torna-o mais barato para utili-

36 As metas de redução de emissões para os países do Anexo I para que os níveis de emissão fiquem $5 \%$ abaixo dos de 1990 variaram de $6 \%$ para o Japão, Canadá, Hungria e Polônia até $8 \%$ de redução para alguns países da União Européia e Europa Oriental. Alguns países como Federação Russa, Nova Zelândia e Ucrânia poderiam manter seus níveis de emissões como estavam e outros poderiam até mesmo aumentar, como Austrália (8\%), Islândia (10\%) e Noruega (1\%).

37 Os valores correspondentes em milhões de toneladas de carbono foram de, respectivamente, 314, 215 , 28 , e 139. 
zação por determinada indústria, o imposto sobre carbono torna-o mais caro e, portanto, desloca a demanda pelo mesmo para outras regiões. Quanto aos termos de troca, obtiveram-se perdas nos setores de eletricidade, indústrias intensivas em energia e outras indústrias e serviços. Em relação ao cenário anterior, houve uma piora significativa nos setores de indústrias intensivas em energia (de um ganho US $\$ 212$ milhões para uma perda de US\$191 milhões) e uma melhora nos termos de troca do setor agropecuário (perda de US\$214 milhões para um ganho de US\$ 90 milhões).

Tabela 6 - Decomposição do bem-estar no Brasil por setor - US \$ milhões

\begin{tabular}{lcc}
\hline Setores & Efeito alocativo & Termos de troca \\
\hline Agropecuária & 15,89 & 90,34 \\
Carvão & $-5,61$ & 11,96 \\
Petróleo cru & $-3,28$ & 82,67 \\
Gás natural & $-1,11$ & 0,03 \\
Derivados P\&C & $-69,71$ & 27,75 \\
Eletricidade & $-11,57$ & $-72,42$ \\
Ind. Int. Energia & 74,88 & $-191,41$ \\
Out. Ind. e Serv. & 796,94 & $-158,53$ \\
\hline Total & 796,42 & $-209,6$ \\
\hline
\end{tabular}

Fonte: Valores resultantes da simulação do cenário Alcal.

A introdução do sistema de comércio de permissão de emissões trouxe um elemento novo para a análise de decomposição de bem-estar: o fluxo de divisas do comércio de emissões (representado por $\mathrm{CO}_{2}$ Trade na Tabela 5). ${ }^{38} \mathrm{O}$ fluxo monetário decorrente do comércio de créditos de emissão de $\mathrm{CO}_{2}$ deve ser compensado por um correspondente fluxo de divisas do comércio de bens e serviços. Esta situação está ilustrada na Tabela 7, na qual se observa que, no caso do Brasil, o saldo positivo de divisas decorrentes da redução de emissões $\left(\mathrm{CO}_{2}\right.$ Trade) possibilitou um déficit adicional em conta corrente (CCOR) de igual montante.

Tabela 7 - Fluxo monetário internacional no cenário de comércio de emissões - US\$ milhões

\begin{tabular}{|c|c|c|c|c|}
\hline País Fluxo & $\mathrm{CO}_{2}$ Trade & CCOR & CCAP & Total BP \\
\hline Brasil & 65 & -22025 & 21960 & -1 \\
\hline EUA & -3246 & -146962 & 150221 & 14 \\
\hline México & 98 & 13387 & -13486 & 0 \\
\hline Canadá & -394 & 18415 & -18020 & 1 \\
\hline RMERC & 68 & -5490 & 5422 & 0 \\
\hline RALCA & 170 & -21001 & 20830 & -1 \\
\hline UE & -2029 & 94712 & -92680 & 3 \\
\hline OANEX1 & -3008 & 107873 & -104861 & 4 \\
\hline OGEMISS & 7944 & 41438 & -49402 & -21 \\
\hline ROW & 252 & -80346 & 80093 & -1 \\
\hline Total & -78 & 0 & 77 & -1 \\
\hline
\end{tabular}

Fonte: Valores resultantes da simulação do cenário Alcal.

38 O sinal positivo indica venda de permissões, e o sinal negativo, compra. 
Observa-se que os principais vendedores de permissões de emissão foram aqueles países/regiões que não foram restringidos em suas emissões de $\mathrm{CO}_{2}$ diretamente. A região OGEMISS obteve US $\$ 7,9$ bilhões e colocou-se como o principal fornecedor de permissões de emissões do modelo. A razão para isso deve-se ao fato dessa região aparecer como grande poluidora e, portanto, com grande potencial para reduzir emissões. O Brasil também se tornou um vendedor líquido de emissões no valor de US $\$ 65$ milhões. Os maiores compradores nesse mercado foram, respectivamente, os EUA, OANEX1 e EU, sendo que o primeiro apresentou uma compra equivalente a US\$3,2 bilhões. Essa compra de permissão de emissões das outras regiões explicou quase a totalidade da perda de bem-estar dos EUA da simulação anterior para esta (US $\$ 4,8$ para US $\$ 1,5$ bilhão).

A Tabela 8 mostra que os resultados apontaram um claro declínio dos principais indicadores econômicos nesta simulação em relação à anterior, na qual somente os choques nas tarifas foram implementados. A taxa de crescimento do PIB caiu para todas as regiões, chegando até mesmo a ocasionar recessão nos EUA, Canadá e RMERC. No Brasil, a taxa de crescimento caiu quase pela metade (de $0,17 \%$ - que na primeira simulação não contemplava restrições de $\mathrm{CO}_{2}$ - para $0,1 \%$ ). Apesar de os países não integrantes do Anexo I do Protocolo de Quioto não restringirem suas emissões diretamente, como é o caso do Brasil, as suas participações em um mecanismo de comércio de emissões, como nesta simulação, os coloca como co-responsáveis das emissões dos países do Anexo I. Portanto, sobre os primeiros incide um imposto nominal sobre a emissão de carbono que, conseqüentemente, reduz a produção nos setores que mais utilizam energia.

Tabela 8 - Variação porcentual do produto total e por setor na ALCA

\begin{tabular}{lrrrrrr}
\hline & Brasil & EUA & México & Canadá & RMERC & RALCA \\
\hline PIB (qgdp) & $\mathbf{0 , 1}$ & $-0,01$ & $\mathbf{0 , 0 1}$ & $-0,07$ & $-\mathbf{0 , 0 5}$ & $\mathbf{0 , 3 2}$ \\
Agropecuária & 0,15 & $-0,84$ & $-0,26$ & $-0,26$ & 0,28 & 0,38 \\
Carvão & $-16,3$ & $-18,2$ & $-12,92$ & $-17,2$ & $-14,6$ & $-20,15$ \\
Petróleo cru & $-4,87$ & $-2,87$ & $-2,87$ & $-2,67$ & 0,63 & $-4,79$ \\
Gás natural & $-5,08$ & $-12,27$ & $-7,18$ & $-9,92$ & $-11,82$ & $-19,69$ \\
Derivados P\&C & $-1,6$ & $-4,63$ & $-3,7$ & $-3,1$ & $-3,34$ & 7,93 \\
Eletricidade & 0,58 & $-2,2$ & $-4,08$ & 0,47 & $-2,17$ & $-0,34$ \\
Ind.Int.Energia & 0,38 & $-0,23$ & 0,2 & $-0,15$ & 0,09 & $-0,56$ \\
Out.Ind.e Serv. & $-0,08$ & $-0,04$ & 0,09 & 0 & $-0,08$ & 0,36 \\
CGDS & 0,09 & 0,01 & 0,19 & $-0,07$ & 0,13 & 0,75 \\
\hline
\end{tabular}

Fonte: Valores resultantes da simulação do cenário Alca1.

Como era de se esperar, os setores que mais se contraíram foram aqueles que sofreram a interferência indireta das restrições de emissões via participação no comércio de emissões, ou seja, os de commodities de energia. Os setores mais atingidos no Brasil foram os de carvão $(-16,3 \%)$, gás natural $(-5,1 \%)$, petróleo bruto $(-4,9 \%)$ e derivados de petróleo $(-1,6 \%)$, como ilustrado na Tabela 8. O setor de eletricidade apresentou um pequeno aumento na produção de $0,58 \%$. A razão para esse setor não ter sido atingido pelas restrições de emissões deve-se ao fato de a geração de energia elétrica no Brasil ser feita predominantemente por meio de hidrelétricas, modo de geração de energia que não gera emissão de carbono. ${ }^{39}$

39 Não é o caso, por exemplo, de países que têm o carvão e petróleo como insumo básico para a geração de eletricidade, como, por exemplo, EUA (-2,2\%), México $(-4,1 \%)$ e OGEMISS $(-5,33 \%)$, onde se encontram China e Índia (grandes produtores de carvão). 


\section{Impactos ambientais}

Ao contrário da simulação anterior, este cenário produziu resultados ambientais positivos (diminuição) no que diz respeito à redução de emissões de $\mathrm{CO}_{2}$ em todas as regiões do modelo (Tabela 9). Países/regiões da ALCA, como Brasil, EUA, México e RALCA que anteriormente tiveram suas emissões aumentadas em virtude da formação da área de livre-comércio, nesta simulação reduziram suas emissões em 3,7\%, 10,9\%,4,6\% e 6,1\%, respectivamente. A maior redução de $\mathrm{CO}_{2}$ ficou por conta de OGEMISS $(-16,3 \%)$ tendo como maior responsável para este resultado a redução das emissões da commodity carvão $(-26,4 \%)$. Com efeito, esta commodity foi a maior responsável pela redução de emissões em quase todas as regiões, e isto se deveu ao aumento do seu preço no mercado mundial e a conseqüente redução do seu uso. ${ }^{40}$

A segunda maior fonte de redução de emissões ficou por conta do setor de gás natural, que no RALCA foi o protagonista principal, atingindo um arrefecimento de 20,1\%. Esta commodity só perdeu a segunda posição no Brasil e México, cujas maiores reduções, depois do carvão, tiveram origem no petróleo cru. As commodities que geraram as menores reduções nas emissões foram as de derivados $\mathrm{P} \& \mathrm{C}$ e eletricidade.

Tabela 9 - Emissões totais e por commodity de energia (variação \%)

\begin{tabular}{lrrrrrr}
\hline & Total & Carvão & Petróleo cru & Gás natural & $\begin{array}{c}\text { Derivados } \\
\text { P\&C }\end{array}$ & Eletricidade \\
\hline Regiões & & & & & & $-0,01$ \\
\hline Brasil & $-3,69$ & $-14,34$ & $-7,62$ & $-5,1$ & $-1,32$ & $-2,06$ \\
EUA & $-10,88$ & $-18,21$ & $-11,09$ & $-11,64$ & $-4,16$ & $-3,96$ \\
México & $-4,59$ & $-12,77$ & $-8,34$ & $-7,02$ & $-3,04$ & $-0,39$ \\
Canadá & $-7,85$ & $-15,18$ & $-6,77$ & $-11,62$ & $-1,85$ & $-1,89$ \\
RMERC & $-6,98$ & $-14,29$ & $-11,12$ & $-11,65$ & $-1,16$ & $-0,09$ \\
RALCA & $-6,09$ & $-14,67$ & $-5,1$ & $-20,12$ & $-1,16$ & $-1,63$ \\
UE & $-5,4$ & $-14,69$ & $-11,44$ & $-7,21$ & $-0,05$ & $-1,14$ \\
OANEX1 & $-7,72$ & $-15,55$ & $-8,78$ & $-6,44$ & $-3,82$ \\
OGEMISS & $-16,33$ & $-26,36$ & $-9,7$ & $-9,23$ & $-3,33$ & $-1,32$ \\
ROW & $-6,64$ & $-14,59$ & $-8,1$ & $-7,23$ & $-2,4$ & \\
\hline
\end{tabular}

Fonte: Valores resultantes da simulação do cenário Alcal.

A Tabela 10 apresenta a Matriz de Contabilidade Social do Brasil (MCS) para a simulação Alcal. ${ }^{41}$ A apresentação deste instrumento deve-se ao fato de se desejar ilustrar o mecanismo de funcionamento do comércio de emissões em determinada região. Existem doze tipos de agentes envolvidos nas transações dessa matriz. As oito primeiras entradas (agropecuária, carvão, petróleo cru, gás natural, produtos derivados de petróleo e carvão, eletricidade, indústrias intensivas em energia, e outras indústrias e serviços) representam a matriz de insumo-produto. As quatro seguintes (terra, trabalho, capital e recursos naturais) são os fatores de produção. Um agente privado doméstico (PHH), o governo (GOV), um setor de investimento (CGDS), o agente doméstico regional (RHH), uma agência de carbono (CAG), e os saldos dos fluxos comerciais com o setor externo (ROW) completam a matriz. As entradas nas colunas representam os pagamentos feitos, enquanto que as linhas, os recebimentos ocorridos no cálculo da MCS.

40 Nesta simulação o preço médio do carvão na região OGEMISS aumentou $87 \%$. Este resultado ficou bem acima do das outras regiões, cujo aumento ficou em torno de $30 \%$.

41 A Matriz de Contabilidade Social é um conveniente instrumento de análise, uma vez que mostra uma situação de equilíbrio em que todas as fontes de renda são exauridas nos gastos de todos os agentes. 


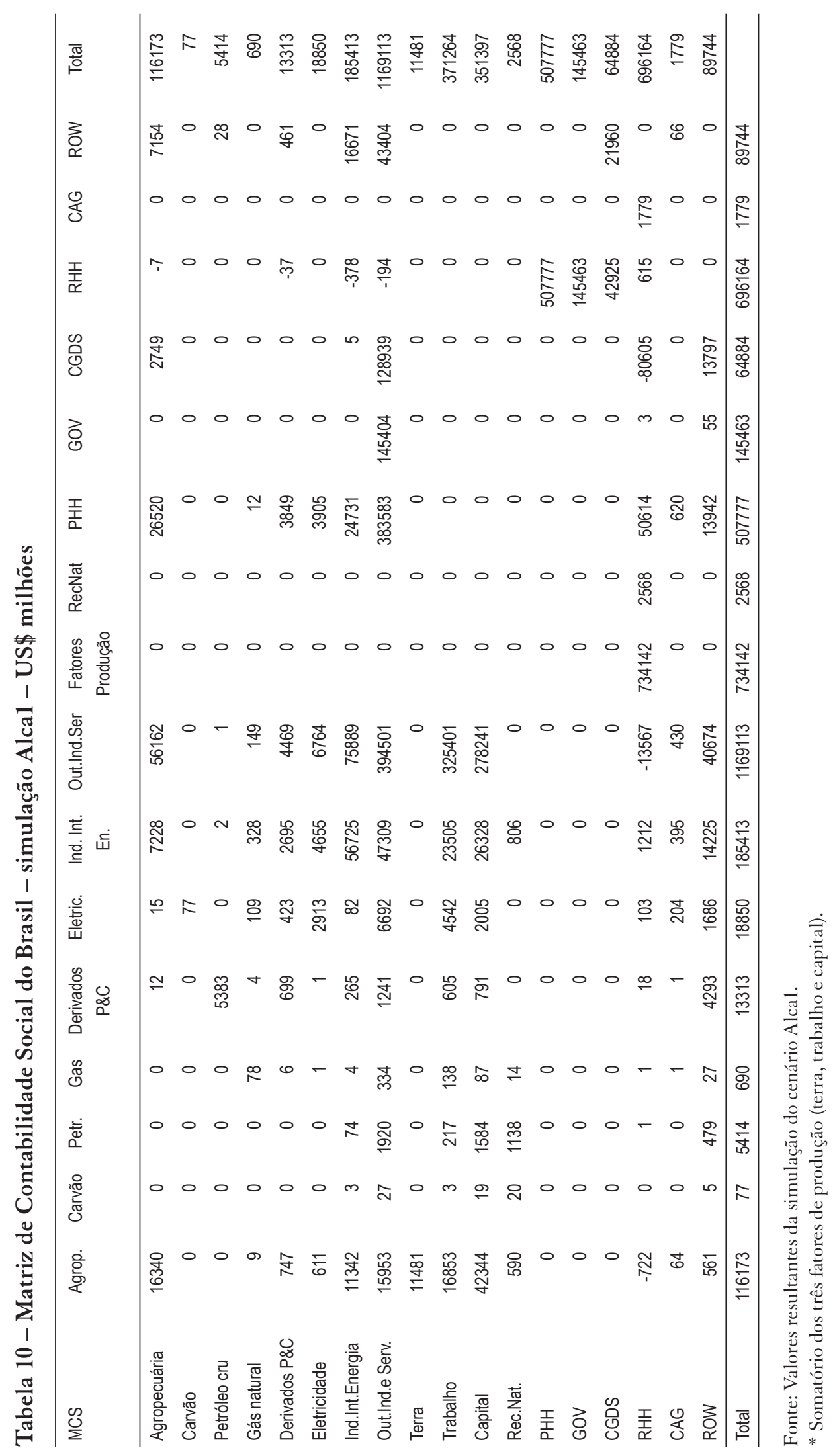


Uma forma de se interpretar os fluxos de renda associados com o comércio de emissões é assumir que a restrição de emissões é imposta por meio de um mercado doméstico de direitos de emissões. As receitas da venda desses direitos (receita do imposto sobre emissão de $\mathrm{CO}_{2}$ ) são recebidas por uma espécie de Agência de Carbono (CAG) que, no Brasil, receberiam um total de US\$ 1,7 bilhão. Desta receita, 34,8\% (US\$ 620 milhões) seriam oriundas do agente privado doméstico (PHH), 24,2\% (US $\$ 430$ milhões) do setor de outras indústrias e serviços, 22,2\% (US\$395 milhões) seriam referentes aos pagamentos feitos pelas indústrias intensivas em energia, $11,5 \%$ (US\$ 204 milhões) pelo setor de eletricidade, e aproximadamente 3\% (US\$ 64 e US\$ 66 milhões, respectivamente) dos setores agropecuário e ROW (resto do mundo na sigla em inglês). O valor de US\$66 milhões referentes à receita do comércio de emissões com os outros países do modelo encontra-se representado por um pagamento efetuado pelo ROW. ${ }^{42}$

A Tabela 11 ilustra a origem das receitas obtidas pela CAG pelo uso das commodities de energia pelos agentes. Cerca de $80 \%$ dessas receitas são originadas do uso dos derivados de petróleo e carvão. O gasto do agente privado regional (PHH) pelo uso dessa commodity chega a US\$ 618 milhões de um total de US\$ 620 milhões, dos quais 92\% são de origem doméstica (US\$ 571 milhões). O setor elétrico paga cerca de US $\$ 157$ milhões pela utilização de carvão, sendo que $83 \%$ desse montante referem-se a este produto com origem no exterior (US\$131 milhões).

Tabela 11 - Origem das receitas da Agência de Carbono no Brasil - US \$ milhões

\begin{tabular}{|c|c|c|c|c|c|c|c|c|c|}
\hline \multirow[b]{2}{*}{ Setor } & \multicolumn{2}{|c|}{ Carvão } & \multicolumn{2}{|c|}{ Petróleo cru } & \multicolumn{2}{|c|}{ Gás natural } & \multicolumn{2}{|c|}{ Derivados P\&C } & \multirow[b]{2}{*}{ TOTAL } \\
\hline & Dom & Imp & Dom & $\operatorname{Imp}$ & Dom & $\operatorname{Imp}$ & Dom & $\operatorname{Imp}$ & \\
\hline Agropecuária & 0 & 0 & 0 & 0 & 1,27 & 0 & 55,26 & 7,1 & 63,63 \\
\hline Carvão & 0 & 0 & 0 & 0 & 0 & 0 & 0 & 0 & 0 \\
\hline Petróleo cru & 0 & 0,01 & 0 & 0 & 0 & 0 & 0,01 & 0 & 0,02 \\
\hline Gás natural & 0 & 0 & 0 & 0 & 0 & 0 & 0,43 & 0,16 & 0,6 \\
\hline Derivados P\&C & 0 & 0 & 0 & 0 & 0,50 & 0 & 0 & 0 & 0,51 \\
\hline Eletricidade & 26,04 & 130,77 & 0 & 0 & 13,75 & 0 & 31,65 & 1,94 & 204,16 \\
\hline Ind. Int. Energia & 0,07 & 96,12 & 0,36 & 0,27 & 43,17 & 0,07 & 190,67 & 64,13 & 394,85 \\
\hline Out. Ind. e Serv. & 0,02 & 2,93 & 0,08 & 0,06 & 19,87 & 0,08 & 347,94 & 58,89 & 429,87 \\
\hline CGDS & 0 & 0 & 0 & 0 & 0 & 0 & 0 & 0 & 0 \\
\hline $\mathrm{PHH}$ & 0 & 0 & 0 & 0 & 1,69 & 0,03 & 571,04 & 47,23 & 619,99 \\
\hline Total & 26,13 & 229,83 & 0,44 & 0,33 & 80,25 & 0,18 & 1197,00 & 179,45 & 1713,63 \\
\hline
\end{tabular}

Fonte: Valores resultantes da simulação do cenário Alcal.

Os resultados obtidos na simulação do experimento Alcal, tanto na avaliação do bem-estar econômico como na atividade produtiva, sugerem que a piora destes indicadores em relação ao experimento Alca foi devido basicamente aos choques de redução de emissão de $\mathrm{CO}_{2}$. Estes resultados, de certa forma esperados, foram uma conseqüência da modelagem do experimento que permitiu que o custo de abatimento de emissões fosse internalizado por todos os países do modelo, sendo que esse abatimento foi de forma direta para os países do Anexo I, e indiretamente via mecanismo de mercado do comércio de emissões, para os países de fora do Anexo I.

42 A divergência desse valor em relação aos US\$ 65 milhões exibidos nas Tabelas 5 e 7 dá-se em razão de arredondamentos feitos para os cálculos na equação deste item na MCS. 


\section{CONSIDERAÇÕES FINAIS}

Neste trabalho foram simulados dois cenários: o primeiro, com a suposição de remoção completa das tarifas de importação e exportação entre os membros da ALCA, mostrou que a desoneração tarifária traria melhoria do bem-estar econômico basicamente para todas as regiões envolvidas nesse acordo de comércio, embora com aumento das emissões de $\mathrm{CO}_{2}$. No Brasil, esses ganhos viriam principalmente da melhor alocação dos recursos produtivos nos setores denominados "outras indústrias e serviços" (setor mais protegido antes da simulação) e "derivados de petróleo e carvão". A atividade econômica (PIB) seria afetada positivamente, sendo os setores de derivados de petróleo e agropecuário os maiores responsáveis por tal desempenho. $\mathrm{O}$ aumento da emissão de $\mathrm{CO}_{2}$ seria gerado basicamente nos setores de produção de petróleo e seus derivados.

O segundo, incorporando choques exógenos de redução de emissões, diminuiria consideravelmente os efeitos nocivos do comércio sobre o meio ambiente, mas com significante redução no bem-estar econômico alcançado no primeiro cenário. Ou seja, neste trabalho, com esse modelo, foi encontrado um trade-off entre as políticas de promoção do livre-comércio no âmbito da ALCA e as de preservação do meio ambiente (representadas pelo Protocolo de Quioto).

Esse resultado sugere que um determinado país que adotasse um comportamento free rider na hipótese de consolidação da ALCA, não participando do comprometimento de redução de emissões, seria beneficiado em relação aos demais países que adotassem outra postura. Assim, não bastassem os problemas puramente comerciais que prejudicam o processo de criação da ALCA, tem-se também essa questão de ordem ambiental que pode afetar a competitividade dos países envolvidos em tal acordo. O comércio de emissões poderia ser uma saída importante para esse problema porque ajudaria a reduzir a emissão de $\mathrm{CO}_{2}$ na atmosfera ao mesmo tempo que geraria renda para os países em desenvolvimento.

No contexto inevitável que se configura atualmente a implantação do Tratado de Quioto, a melhor alternativa de implementação da ALCA, tanto do ponto de vista ambiental quanto econômico, seria que esta se desse num contexto de comprometimento de todos os países do mundo (principalmente dos EUA). No Brasil, a possibilidade de participação do comércio de emissões, além de gerar bem-estar econômico, produziria desde já a redução das emissões de $\mathrm{CO}_{2}$ consideradas por este trabalho. Portanto, nas negociações da ALCA deve-se levar em consideração que a execução de um acordo de proporção global, como o Tratado de Quioto, não deveria ser tratada de forma isolada dos acordos de formação de blocos comerciais. A não observância deste aspecto pode aumentar os conflitos (já numerosos) existentes no processo de negociações para a formação da ALCA.

\section{REFERÊNCIAS}

Antweiler, W.; Copeland, B.; Taylor, S. Is free trade good for the environment? NBER Working Paper n. 6707, 1998.

Azevedo, A. Análise empírica do impacto econômico da ALCA e da consolidação do Mercosul sobre o Brasil. Texto para discussão n. 12. Porto Alegre: Universidade Federal do Rio Grande do Sul, 2003. Mimeografado.

Baumann, R. ALCA: Prejuízos inevitáveis ou oportunidade para promover mudanças?, In: Baumann, R. (org.), A ALCA e o Brasil: uma contribuição ao debate. Brasília: IPEA/CEPAL, 2003.

Baldwin, R.; Venables A. Regional economic integration. In: Grossman, G.; Rogoff, K. (eds.), Handbook of international economics, vol. 3. Amsterdam: North Holland, p. 1597-1644, 1995. 
Bohringer, C.; Pahlke, A. Environmental tax reforms and the prospects for a double dividend - An intertemporal general equilibrium analysis for Germany. Working Paper, Boulder: University of Colorado, 1997.

Bouzas, R. El proceso del ALCA: incertidumbres y desafíos. Indicadores Econômicos FEE, 29, p. 9-24, 2001.

Burniaux, J. M.; Truong, P. T. GTAP-E: an energy-environmental version of the GTAP Model. GTAP Technical Paper N. 16, Center for Global Trade and Analysis, Purdue University, 2002. Disponível em: http://www.gtap.agecon.purdue.edu/ Acesso: Dez/2003.

Domingues, E. P. Dimensão regional e setorial da integração brasileira na Área de Livre Comércio das Américas. 2002. Tese (Doutorado), Universidade de São Paulo, São Paulo.

Feijó, F. T. Alca e Protocolo de Quioto: uma avaliação integrada utilizando o GTAP-E. 2005. Tese (Doutorado), Universidade Federal do Rio Grande do Sul, Porto Alegre.

Fritz, O. M.; Sonis, M.; Hewings, G. J. D. A Miyazawa analysis of interactions between polluting and non-polluting sectors. Structural Change and Economic Dynamics, v. 9, p. 289-305, 1998.

Grossman, G. M.; Krueger, A. B. Environmental impacts of a North American free trade agreement. NBER Working Paper n. 3914, November 1991.

. Environmental impacts of a North American free trade agreement. In: Garber, P. The MexicoUS free trade agreement. Cambridge, Ma: MIT Press, 1993.

Haddad, E. A.; Hewings, G. J. D. The theoretical specification of B-MARIA. Discussion Paper 97-t-5. University of Illinois at Urbana-Champaign, Regional Economics Applications Laboratory, 1997.

Hertel, T. (ed.) Global trade analysis: modeling and applications. New York: Cambridge University Press, 1997.

Lee, H. An emissions data base for integrated assessment of climate change policy using GTAP. GTAP Technical Paper N. 1143, Center for Global Trade and Analysis, Purdue University, 2003. Disponível em: http://www.gtap.agecon.purdue.edu/ Acesso em: Jul/2004.

Ministério da Ciência e Tecnologia. Efeito estufa e a convenção sobre a mudança no clima. 1999. Disponível em: www.mct.gov.br Acesso: Agosto/2004.

. Pontos de vista do Brasil sobre o mecanismo de desenvolvimento limpo (CDM). 1999. Disponível em: www.mct.gov.br Acesso: Agosto/2004.

OCDE. Action against climate change: the Kyoto Protocol and beyond. OCDE Publications Service, 1999.

Panagariya, A. An empirical estimate of static welfare losses to México from NAFTA. Center of International Economics, University of Maryland, 1997.

Pereira, A.; May, P. Economia do aquecimento global. In: May, Peter; Lustosa, Maria Cecília; Vinha, Valéria da (orgs.), Economia do meio ambiente: teoria e prática. Rio de Janeiro: Elsevier, 2003.

Protocolo de Quioto, 1997. Disponível em: www.mct.gov.br. Acesso: Fev/2003.

Rutherford, T.; Montgomery, W.; Bernstein, P. CETM: a dynamic general equilibrium model of global energy markets, carbon dioxide emissions and international trade. Working Paper 97-3, Boulder: University of Colorado, 1997.

Sen, A. Neo-classical and neo-Keynesian theories of distribution. Economic Record, v. 39, p. 54-64, 1963.

Seroa da Motta, R. Padrão de consumo, distribuição de renda e o meio ambiente no Brasil. Rio de Janeiro: IPEA, jan., 2002. (Texto para Discussão, 856). Disponível em: www.ipea.gov.br Acesso: Jun/2003.

Seroa da Motta, R; Ferraz, C.; Young, C. E. F.; Austin, D.; Faeth, P. O. Mecanismo de desenvolvimento limpo e o financiamento de desenvolvimento sustentável no Brasil. IPEA, 2000. (Texto para discussão n. 761). Disponível em: www.ipea.gov.br Jun/2003. 
Tobey, J. The effects of domestic environmental policies on patterns of world trade: an empirical test. Kyklos, v. 43, n. 2, p. 191-209, 1990.

Tourinho, O.; Andrade, S. Cenários para o início do milênio no Brasil. IPEA, abr. 1998. Mimeografado.

Tourinho, O.; Kume, H.; Pedroso, A. Elasticidades de Armington para o Brasil-1986-2002: novas estimativas. Rio de Janeiro: IPEA, 2003. (Texto para Discussão: 974) Disponível em: www.ipea.gov.br Acesso: Out/2003.

Tourinho, O.; Seroa da Motta, R.; Alves, Y. Uma aplicação ambiental de um modelo de equilíbrio geral. Rio de Janeiro: IPEA, 2003. (Texto para Discussão: 976). Disponível em: www.ipea.gov.br Acesso: Dez/2003.

Young, C. Trade and the environment: linkages between competitiveness and industrial pollution in Brazil. In: Munasinghe, M. (ed.), Report to the research project making long-term growth more sustainable: Brazil country case study. Washington: The World Bank, 2002.

\section{ANEXo A - Estrutura dE PRODUÇÃo DO GTAP-E}

A estrutura de produção do GTAP-E é adaptada de várias proposições feitas por modelos de EGC que incluem a característica de substituição de energia. No nível superior da Figura A.1, governada por uma função Leontief, existe uma proporção fixa combinando o valor adicionado e bens intermediários. Com relação à estrutura de produção padrão do modelo original GTAP, a primeira modificação se refere à retirada do insumo "energia" do "ninho" dos insumos intermediários e a sua posterior inclusão no ninho do valor adicionado. ${ }^{43}$

Figura A.1 - Nova estrutura de produção do GTAP (GTAP-E)

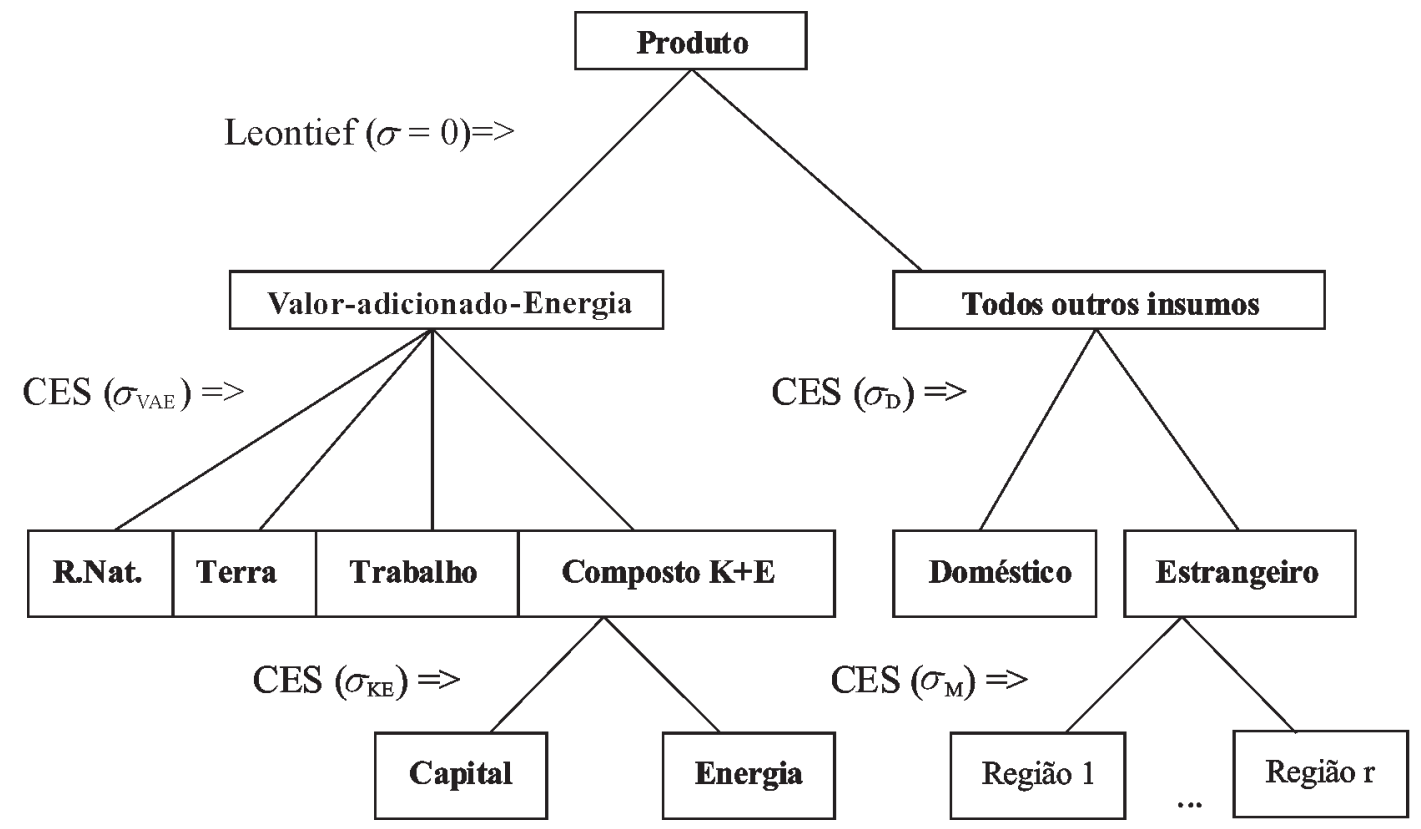

Fonte: Burniaux e Truong (2002).

43 O insumo "energia”, quando não utilizado diretamente como fonte de energia, mas sim transformado para tornar-se parte de outro produto, permanece no ninho dos insumos intermediários. 
Como pode ser observado na Figura A.1, a nova formação da estrutura de produção tem agora um ninho chamado de "valor-adicionado-Energia", em que duas funções CES compõem este nível. Uma importante modificação deste modelo em relação ao original, que deve ser destacada, é a possibilidade de a elasticidade de substituição neste ninho (parâmetro $\sigma_{\mathrm{VAE}}$ ) poder assumir valores diferentes para as diferentes regiões do modelo. Para o Brasil, por exemplo, o modelo foi calibrado com valores iguais a quatro para o carvão e 1,26 para derivados do petróleo e eletricidade. ${ }^{44}$

Na Figura A.2, subdivisão seguinte da estrutura de produção, o composto de energia dessa estrutura é separado em grupos elétrico e não-elétrico. Neste último, também governado por uma função CES $\left(\sigma_{\mathrm{NELE}}\right)$, é permitido algum grau de substituição entre estes grupos. O setor não-elétrico, por sua vez, subdivide-se em carvão, cuja fonte pode ser doméstica ou externa $\left(\sigma_{\mathrm{D}}\right)$, e em outros combustíveis $\left(\sigma_{\mathrm{NCAR}}\right)$. Finalmente, no nível mais baixo, têm-se mais três grupos que se originam de outros combustíveis. Estes são: gás natural, petróleo e combustíveis derivados de petróleo e carvão, em que cada um desses combustíveis é escolhido de acordo com a suposição das elasticidades de Armington.

Figura A.2 - Estrutura de substituição entre fontes de energia

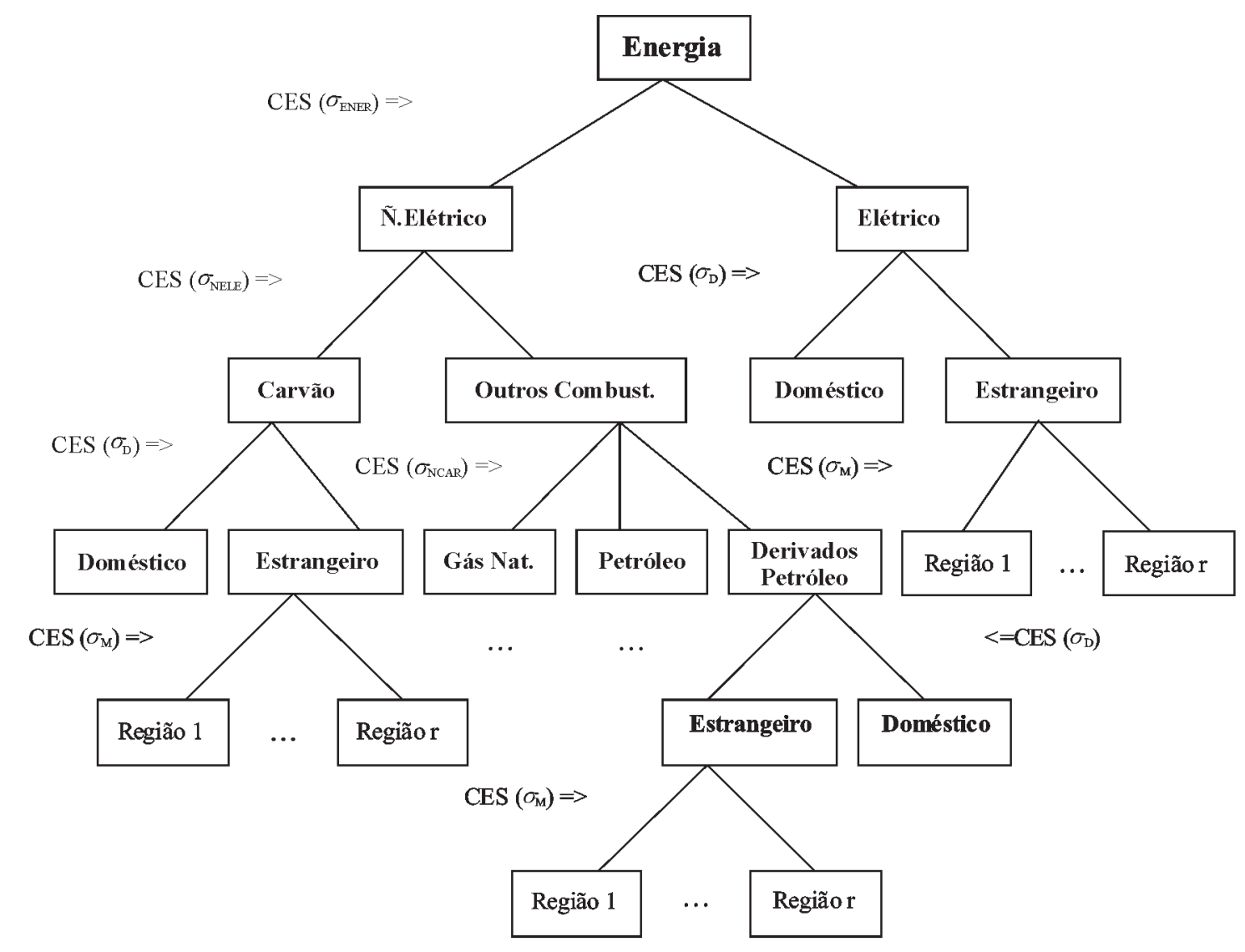

Fonte: Elaboração própria adaptada de Burniaux e Truong (2002).

44 Calibrar um modelo EGC significa atribuir valores numéricos aos parâmetros das equações para a adequação da base de dados. Ou, colocado de outra forma, os parâmetros de uma economia virtual (no computador) devem ser calibrados de forma tal que o equilíbrio reproduza as transações observadas nos dados. 


\section{Estrutura de consumo}

Pelo lado do consumo, o GTAP-E tem basicamente a mesma estrutura do GTAP padrão, ou seja, consumo de governo (consumo por domésticos de bens fornecidos publicamente) comandado por uma função Cobb Douglas para todas as commodities e o consumo privado por uma forma funcional CDE (do termo em inglês constant-difference of elasticities). Entretanto, o GTAP-E possui algumas peculiaridades que devem ser ressaltadas. Primeiro, o consumo do governo é agora dividido em dois "compostos", um com commodities de energia e outro não. Segundo, é que a elasticidade de substituição entre as commodities no interior do composto de energia (inner) precisa ser diferente da elasticidade externa ao composto (outer), e esta última diferente de um, tal como ilustrado na Figura A.3..$^{45}$ Esta é uma condição para que a estrutura do GTAP-E não fique equivalente à do modelo padrão e, desta forma, permita substituição entre e dentro dos subgrupos energia e não-energia. Os critérios adotados para calibrar estas funções foram baseados nos trabalhos de Rutherford et al. (1997) e Bohringer e Pahlke (1997).

Figura A.3 - Estrutura de consumo do governo

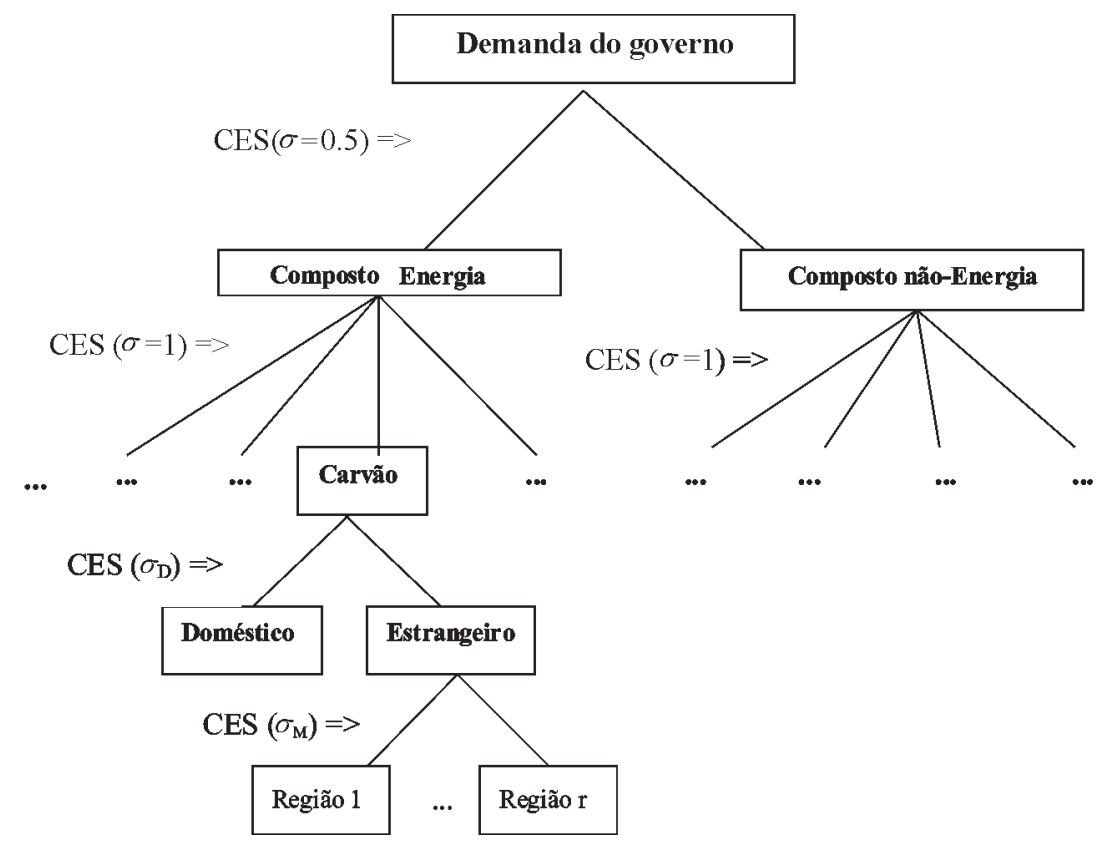

Fonte: Burniaux e Truong (2002).

Para o consumo de bens privados é utilizado o expediente de desagregar o grupo de commodities de energia (carvão, petróleo cru, eletricidade, gás natural, e derivados de petróleo e carvão) da estrutura padrão existente de forma funcional CDE, e posteriormente agregá-lo em um novo composto (Composto Energia na Figura A.4). Isto somente é possível porque os parâmetros de substituição e renda do modelo para o grupo de commodities de energia são basicamente os mesmos para esses produtos. ${ }^{46}$ Esta é uma condição necessária imposta pela teoria de estruturas CDE para que essas commodities possam ser agregadas com os mesmos parâmetros que os componentes in-

45 Ou seja, $\sigma_{\text {inner }} \neq \sigma_{\text {outer }} \neq 1$.

46 Com exceção para os produtos derivados de petróleo e carvão. 
dividuais. Posteriormente, para esse composto é especificada uma subestrutura CES para permitir uma flexível substituição entre os seus elementos.

Figura A.4 - Estrutura do consumo privado

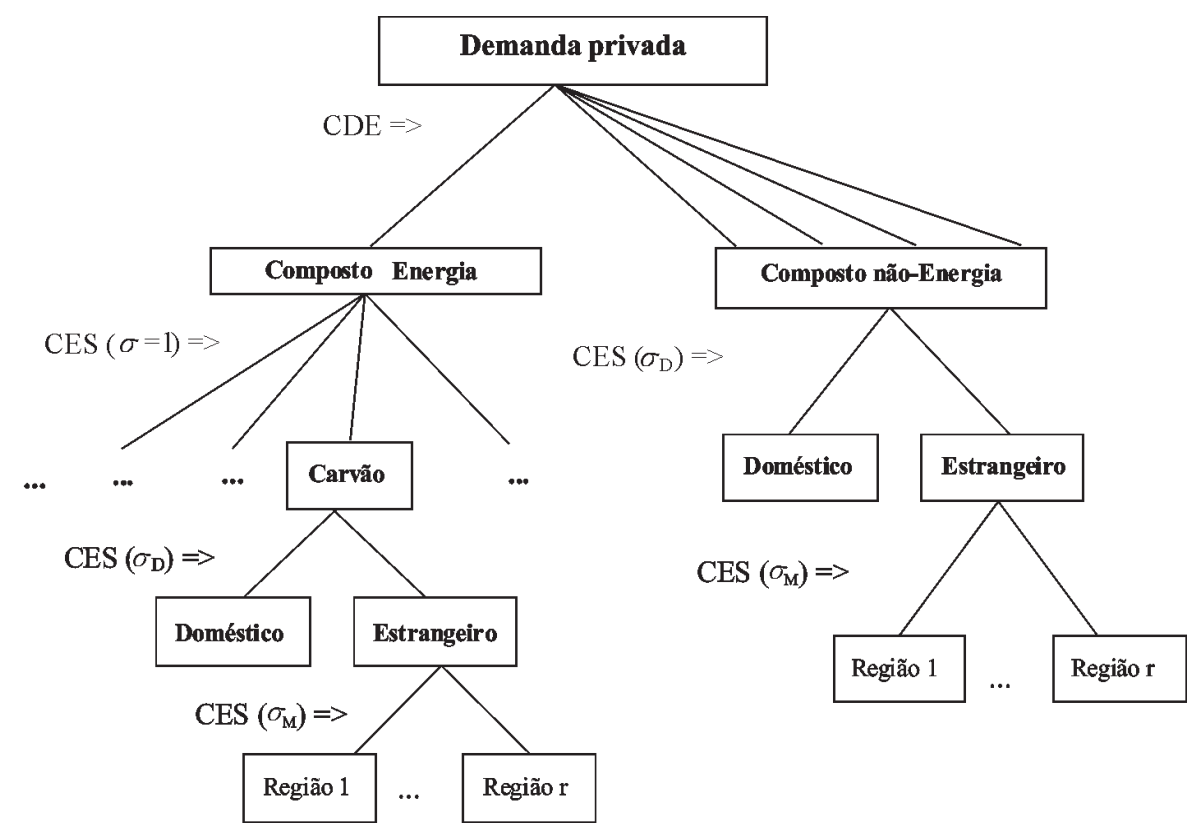

Fonte: Burniaux e Truong (2002). 


\section{ANEXo B}

Tabela A.1 - Participação dos setores na demanda por energia nas regiões da ALCA

\begin{tabular}{|c|c|c|c|c|c|c|c|c|c|}
\hline & Agropecuária & Carvão & $\begin{array}{l}\text { Petróleo } \\
\text { cru }\end{array}$ & $\begin{array}{c}\text { Gás } \\
\text { natural }\end{array}$ & $\begin{array}{c}\text { Derivados } \\
\text { P\&C }\end{array}$ & Eletricidade & $\begin{array}{l}\text { Ind.Int. } \\
\text { Energia }\end{array}$ & $\begin{array}{l}\text { Out.Ind. } \\
\text { e Serv. }\end{array}$ & Total \\
\hline \multicolumn{10}{|l|}{ Brasil } \\
\hline Carvão & 0.000 & 0.526 & 0.410 & 0.000 & 0.000 & 0.468 & 0.139 & 0.003 & 0.070 \\
\hline Petróleo cru & 0.000 & 0.000 & 0.001 & 0.000 & 0.940 & 0.000 & 0.001 & 0.000 & 0.429 \\
\hline Gás natural & 0.013 & 0.019 & 0.086 & 0.922 & 0.000 & 0.053 & 0.078 & 0.029 & 0.030 \\
\hline Derivados P\&C & 0.826 & 0.327 & 0.383 & 0.076 & 0.059 & 0.154 & 0.577 & 0.710 & 0.338 \\
\hline Eletricidade & 0.161 & 0.128 & 0.121 & 0.002 & 0.000 & 0.325 & 0.205 & 0.258 & 0.133 \\
\hline Total $^{*}$ & 1.000 & 1.000 & 1.000 & 1.000 & 1.000 & 1.000 & 1.000 & 1.000 & 1.000 \\
\hline \multicolumn{10}{|l|}{ EUA } \\
\hline Carvão & 0.007 & 0.922 & 0.000 & 0.000 & 0.000 & 0.694 & 0.073 & 0.007 & 0.192 \\
\hline Petróleo cru & 0.000 & 0.000 & 0.235 & 0.008 & 0.942 & 0.000 & 0.000 & 0.000 & 0.321 \\
\hline Gás natural & 0.626 & 0.006 & 0.364 & 0.992 & 0.000 & 0.213 & 0.310 & 0.203 & 0.168 \\
\hline Derivados P\&C & 0.193 & 0.058 & 0.241 & 0.000 & 0.057 & 0.027 & 0.467 & 0.587 & 0.229 \\
\hline Eletricidade & 0.174 & 0.014 & 0.160 & 0.000 & 0.000 & 0.066 & 0.150 & 0.203 & 0.090 \\
\hline Total & 1.000 & 1.000 & 1.000 & 1.000 & 1.000 & 1.000 & 1.000 & 1.000 & 1.000 \\
\hline \multicolumn{10}{|l|}{ México } \\
\hline Carvão & 0.000 & 0.990 & 0.000 & 0.000 & 0.000 & 0.114 & 0.087 & 0.000 & 0.034 \\
\hline Petróleo cru & 0.000 & 0.000 & 0.002 & 0.000 & 0.921 & 0.000 & 0.000 & 0.000 & 0.415 \\
\hline Gás natural & 0.005 & 0.000 & 0.018 & 0.999 & 0.000 & 0.262 & 0.432 & 0.071 & 0.148 \\
\hline Derivados P\&C & 0.745 & 0.006 & 0.928 & 0.000 & 0.079 & 0.534 & 0.382 & 0.749 & 0.336 \\
\hline Eletricidade & 0.250 & 0.004 & 0.052 & 0.000 & 0.000 & 0.090 & 0.099 & 0.180 & 0.067 \\
\hline Total & 1.000 & 1.000 & 1.000 & 1.000 & 1.000 & 1.000 & 1.000 & 1.000 & 1.000 \\
\hline \multicolumn{10}{|l|}{ Canadá } \\
\hline Carvão & 0.002 & 0.000 & 0.000 & 0.000 & 0.000 & 0.567 & 0.074 & 0.003 & 0.101 \\
\hline Petróleo cru & 0.000 & 0.000 & 0.000 & 0.000 & 0.920 & 0.008 & 0.000 & 0.000 & 0.318 \\
\hline Gás natural & 0.092 & 0.202 & 0.999 & 1.000 & 0.004 & 0.246 & 0.316 & 0.309 & 0.206 \\
\hline Derivados P\&C & 0.766 & 0.600 & 0.000 & 0.000 & 0.076 & 0.050 & 0.384 & 0.460 & 0.248 \\
\hline Eletricidade & 0.139 & 0.198 & 0.001 & 0.000 & 0.000 & 0.129 & 0.226 & 0.227 & 0.126 \\
\hline Total & 1.000 & 1.000 & 1.000 & 1.000 & 1.000 & 1.000 & 1.000 & 1.000 & 1.000 \\
\hline \multicolumn{10}{|l|}{ RMERC } \\
\hline Carvão & 0.000 & 0.768 & 0.000 & 0.000 & 0.000 & 0.034 & 0.047 & 0.004 & 0.011 \\
\hline Petróleo cru & 0.000 & 0.034 & 0.792 & 0.003 & 0.958 & 0.000 & 0.061 & 0.000 & 0.375 \\
\hline Gás natural & 0.425 & 0.000 & 0.024 & 0.997 & 0.000 & 0.802 & 0.296 & 0.362 & 0.330 \\
\hline Derivados $\mathrm{P} \& \mathrm{C}$ & 0.564 & 0.197 & 0.163 & 0.000 & 0.042 & 0.059 & 0.430 & 0.491 & 0.217 \\
\hline Eletricidade & 0.011 & 0.000 & 0.022 & 0.000 & 0.000 & 0.104 & 0.166 & 0.143 & 0.067 \\
\hline Total & 1.000 & 1.000 & 1.000 & 1.000 & 1.000 & 1.000 & 1.000 & 1.000 & 1.000 \\
\hline \multicolumn{10}{|l|}{ RALCA } \\
\hline Carvão & 0.015 & 0.913 & 0.004 & 0.005 & 0.000 & 0.106 & 0.083 & 0.014 & 0.028 \\
\hline Petróleo cru & 0.002 & 0.000 & 0.724 & 0.000 & 0.973 & 0.002 & 0.040 & 0.014 & 0.485 \\
\hline Gás natural & 0.097 & 0.029 & 0.092 & 0.962 & 0.000 & 0.449 & 0.442 & 0.075 & 0.163 \\
\hline Derivados P\&C & 0.781 & 0.024 & 0.158 & 0.033 & 0.027 & 0.326 & 0.303 & 0.758 & 0.262 \\
\hline Eletricidade & 0.104 & 0.033 & 0.022 & 0.000 & 0.000 & 0.117 & 0.131 & 0.139 & 0.062 \\
\hline Total & 1.000 & 1.000 & 1.000 & 1.000 & 1.000 & 1.000 & 1.000 & 1.000 & 1.000 \\
\hline
\end{tabular}

Fonte: Base de dados do GTAP (versão 5.4).

* Obs.: $1.000=100 \%$. 